\title{
OPORTUNIDAD DE REFERENCIA EN URGENCIAS PARA LA RED PÚBLICA DEL DISTRITO 2012, 2013 Y DE ENERO A JULIO DE 2014
}

Una tesis presentada para obtener el título de

Magíster en Protección Social

Universidad Santo Tomás, Bogotá

Lina Marcela Acosta Castillo

Marzo de 2015 
Copyright @ 2015 por Lina Marcela Acosta. Todos los derechos reservados. 
UNIVERSIDAD SANTOTOMAS

Dedicatoria

A un ser maravilloso... LDJCC (Q.E.P.D.) 


\section{Agradecimientos}

Al Dr. Ricardo María Cañón Prieto, Personero de Bogotá, por su compromiso, esfuerzo y dedicación por mejorar el Sistema General de Seguridad Social en Salud de los usuarios del sistema en Bogotá. Al Dr. Jaime Rafael Fernández Madriñan, Coordinador del grupo: Personería para la Asistencia en Salud-PAS- de la Personería de Bogotá por su apoyo incondicional, su gran amor y pasión por su ejercicio profesional. Al Dr. Oscar Iván Cañón López, Director de la investigación, a la Dra. Andrea Carolina Reyes y a todas las personas que aportaron su valioso conocimiento en el desarrollo de esta. Por último, al motor de esta investigación que motivó el esfuerzo por demostrar que la atención en salud tiene que ser diferente. LDJCC (Q.E.P.D.). A ellos mil gracias. 


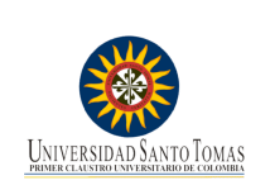

\section{ABSTRACT}

Este estudio busca identificar si existe oportunidad de referencia en los servicios de urgencias para hospitales de la red pública del Distrito el cual surge de la necesidad de mejorar la restitución al derecho en salud en el proceso de referencia para urgencias de la red pública, incentivando el análisis de los hallazgos que permitan gestionar planes de mejora en la prestación del servicio de salud dado que en el Distrito no existe un análisis oportuno y adecuado sobre el tema, lo anterior teniendo como base la información suministrada por la Dirección de Planeación y Sistemas de la Secretaría Distrital de Salud Luego de recibir el 100\% de los reportes de los hospitales a los que se les solicitó la información, se creó una base de datos en Exce ${ }^{\circledR}$, segmentándola por cada año de medición (2012 / 2013 / enero a julio de 2014) con las variables solicitadas. Se realizó el filtro por nivel de complejidad, y se procedió a analizar en primer lugar el bajo nivel de complejidad, en segundo lugar el mediano nivel y en tercer lugar el alto nivel, se excluyeron los hospitales que no reportaron el dato o quienes reportaron información no apta para medición, por no responder la variable. Se calculó el porcentaje de muestra para medición mediante regla de tres, teniendo en cuenta el número de hospitales por nivel de complejidad solicitados. Cada variable se analizó de manera individual, citando el hospital y lo que reportó. Posteriormente se agruparon los datos para presentar los totales y porcentajes de acuerdo a lo que se estaba midiendo, al final de cada variable se presenta un análisis por año y finalmente mediante líneas se grafica el comportamiento de la variable de medición para los años 2012 / 2013 / enero a julio 2014 con el respectivo análisis general y por año, citando hallazgos importantes como: hospitales que no reportan, incongruencia de datos o datos no adecuados para medición por no responder de manera explícita la solicitud, entre otros.

Es necesario mejorar el sistema de información que permita obtener un dato real del número de referencias que se presentan en la red pública del Distrito, sin embargo aunque no es claro si el dato es objetivo, se evidencia un número importante de referencias en el servicio de urgencias.

La Secretaría Distrital de Salud mediante su Circular 030 de 2009, reglamentó la implementación de las herramientas informáticas: Sistema Integral De Referencia y Contrarreferencia -SIRC-Capacidad Instalada y Producción de Servicios (CIP) con el fin de abordar la necesidad existente de evaluar y adecuar políticas a nivel Distrital que permitieran identificar la organización y fortalecimiento de los servicios de salud que se prestan a los usuarios del Distrito, donde marzo de 2012, los hospitales iniciaron el reporte del módulo del Registro Único de Referencia (RUR) cuyo objetivo fue mejorar la eficacia en el sector salud en cuanto a cobertura, oportunidad y disponibilidad de los servicios tanto ambulatorios como hospitalarios ofrecidos por las E.S.E.s. Actualmente se evidencia que los hospitales han mejorado la adherencia a este aplicativo, aumentando el registro. Su cumplimiento permitiría 
contar con un dato objetivo sensible a consolidación y análisis estadístico que proponga estrategias de mejora para el proceso de referencia y contrarreferencia.

Se evidencia una posible falta de oportunidad en el proceso de referencia de los pacientes en el servicio de urgencias, donde ningún hospital analizado reportó referencia de pacientes en el tiempo establecido por el Decreto 4747 de 2007 (6 horas), lo que demuestra que estos se exponen de manera importante a deterioro biosicosocial e incluso la muerte. Por lo anterior, es importante que las EPS garanticen la oportunidad, el acceso y continuidad en el Derecho a la Salud, donde los entes de control competentes realicen vigilancia al cumplimiento del mismo.

Se evidencia que existen pacientes que mueren en la espera de ser trasladados a la unidad de servicio médico especializado que requiere para la atención de su patología, hecho inaceptable, teniendo en cuenta la salud como Derecho y la atención médica en condiciones adecuadas para el tratamiento y rehabilitación. Cabe resaltar que probablemente existe un subregistro importante de pacientes, los cuales, por no existir una base de datos formal para su reporte, son difíciles de medir.

Teniendo en cuenta que los niveles de mediano y alto nivel de complejidad no cuentan con capacidad ociosa para suplir las demandas de atención en salud, sino por el contrario se encuentran en emergencia funcional, es claro que puede estar existiendo una insuficiencia de camas importante en el Distrito para responder a las necesidades en salud de la población, especialmente del régimen subsidiado.

Si bien se requieren otros estudios para precisar el número de camas y servicios que hacen falta, lo importante de esta investigación es sugerir que estos datos de medición sean incluidos en el SIRC,(Sistema Integrado de Referencia y Contrarreferencia de la Secretaría Distrital de Salud) donde también se recomienda que desde la Superintendencia Nacional de Salud se generen parámetros de calidad que permitan monitorear, analizar y actuar en las demoras evidenciadas en los procesos de referencia, disminuyendo el riesgo de morbi-mortalidad de los pacientes. Con base a esto se evidencia la necesidad de:

- Exigir y vigilar el cumplimiento de la norma que hace responsable a las EPS de GARANTIZAR el diseño, organización, documentación y operación del proceso de referencia, donde deben disponer de una red de prestadores de servicios de salud que garantice DISPONIBILIDAD y SUFICIENCIA en TODOS LOS NIVELES DE COMPLEJIDAD.

- La Superintendencia Nacional de Salud debe generar de manera continua estándares de calidad para evaluar tiempos de espera y realizar seguimiento a su cumplimiento. 
- Aumentar el número de estudios que evidencien el número de camas y unidades necesarias para atender las necesidades en salud de la población del Distrito.

- Realizar seguimiento al cumplimiento del registro en el SIRC que deben realizar las E.S.E. para mejorar la calidad en los procesos de referencia y contrarreferencia.

- Es necesario idear estrategias que permitan mejorar la prestación del servicio de salud, mejorando la garantía en el derecho al mismo.

- De acuerdo al análisis, se evidencia que la especialidad médica con mayor demanda es Ginecobstetricia, seguido de Medicina Interna, Cirugía general y Pediatría.

- Es importante que se regule el comportamiento de las EPS en respuesta a la oportunidad en la referencia, teniendo en cuenta que en algunos casos, su red de prestadores no es la adecuada para dar respuesta a la demanda de unidades especializadas.

PALABRAS CLAVE: Oportunidad, referencia, urgencia, urgencia vital, atención, nivel de complejidad 


\section{Contenido}

Dedicatoria.

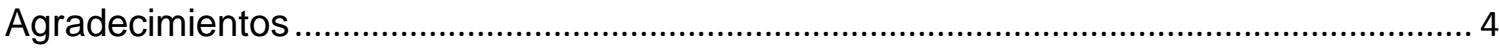

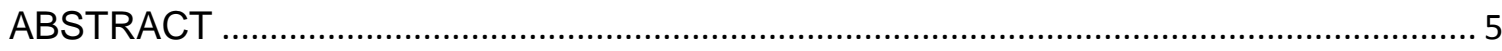

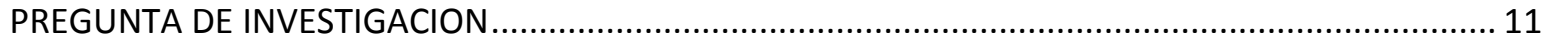

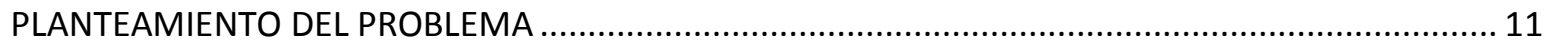

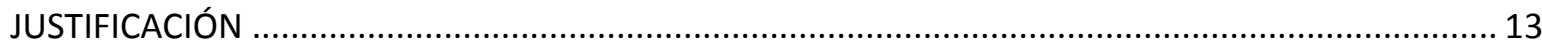

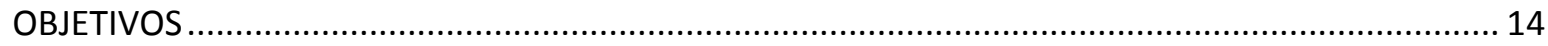

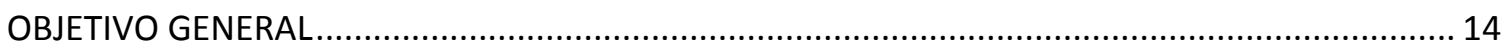

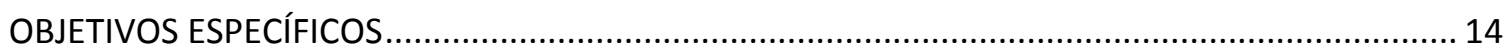

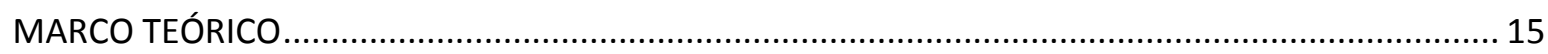

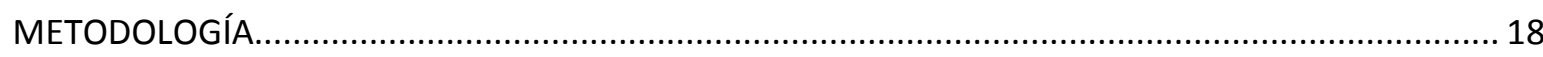

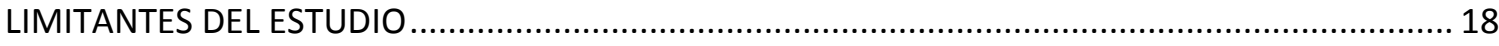

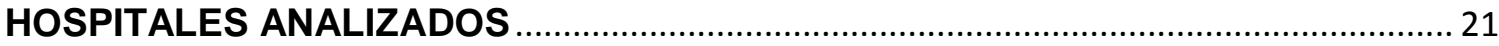

POBLACIÓN QUE ATIENDEN LOS HOSPITALES DE LA RED PÚBLICA .................... 21

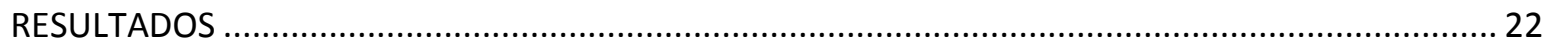

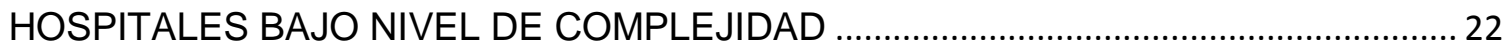

NUMERO DE REFERENCIAS SOLICITADAS EN EL SERVICIO DE URGENCIAS EN EL HOSPITAL CUALQUIER TRIAGE VS NUMERO DE REFERENCIAS EN URGENCIAS VITALES EN LOS AÑOS 2012, 2013 Y DE ENERO A JULIO DE 2014.. 22 NÚMERO DE PACIENTES QUE FALLECEN SIN RECIBIR LA REFERENCIA SOLICITADA.

PROMEDIO EN HORAS ENTRE LA SOLICITUD DE REFERENCIA Y EL EGRESO DE LA INSTITUCION 26 OFERTA DE REFERENCIAS EN URGENCIAS EN LA INSTITUCIÓN........................... 27

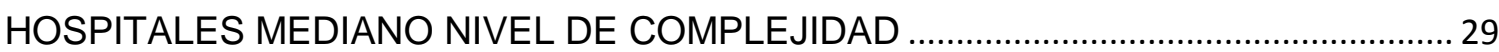

NÚMERO DE REFERENCIAS SOLICITADAS EN EL SERVICIO DE URGENCIAS EN EL HOSPITAL CUALQUIER TRIAGE VS NÚMERO DE REFERENCIAS EN URGENCIAS VITALES EN LOS AÑOS 2012, 2013 Y DE ENERO A JULIO DE 2014.. 29 NÚMERO DE REFERENCIAS ATENDIDAS EN EL SERVICIO DE URGENCIAS.......... 33 NÚMERO DE SERVICIOS TERCERIZADOS CONTRATADOS POR ESPECIALIDAD EN LA INSTITUCION

NÚMERO DE PACIENTES QUE FALLECEN SIN RECIBIR LA REFERENCIA SOLICITADA.

COMPORTAMIENTO DEL PROMEDIO EN HORAS ENTRE LA SOLICITUD DE REFERENCIA Y EL EGRESO DE LA INSTITUCION. 
NÚMERO DE REFERENCIAS SOLICITADAS EN EL SERVICIO DE URGENCIAS EN EL HOSPITAL CUALQUIER TRIAGE VS NÚMERO DE REFERENCIAS EN

NÚMERO DE REFERENCIAS ATENDIDAS EN EL SERVICIO DE URGENCIAS EN LOS TURNOS.

NÚMERO DE SERVICIOS TERCERIZADOS CONTRATADOS POR ESPECIALIDAD EN LA INSTITUCION.

NÚMERO DE PACIENTES QUE FALLECEN SIN RECIBIR LA REFERENCIA SOLICITADA.

COMPORTAMIENTO DEL PROMEDIO EN HORAS ENTRE LA SOLICITUD DE REFERENCIA Y EL EGRESO DE LA INSTITUCION.

NUMERO DE REFERENCIAS NO ATENDIDAS OPORTUNAMENTE POR NO CONTAR CON EL SERVICIO REQUERIDO.

DISCUSIÓN. 48

CONCLUSIÓN. 49

LISTA DE REFERENCIAS 

DISTRITO 2012, 2013 Y DE ENERO A JULIO DE 2014

Autor: Lina M. Acosta Castillo

Director de la Investigación: Oscar Iván Cañón López

Médico y cirujano, Esp Gerencia y Auditoría de la Calidad en Salud. Ms. Economía de la Salud y Farmacoeconomía.

Grupo de investigación Salud y Equidad 
$¿$ ¿xiste oportunidad de referencia en los servicios de urgencias para hospitales de la red pública del Distrito?

\section{PLANTEAMIENTO DEL PROBLEMA}

Durante 5 meses de observación e intervención mediante las visitas administrativas diurnas realizadas por la comisión del Grupo de la Personería para la Asistencia en Salud PAS en los servicios de urgencias de los 22 hospitales del Distrito, se identificó que la atención de urgencias se convierte en un punto importante a la hora de definir la sobrevida del paciente. En Bogotá existen a diario en los hospitales tanto públicos como privados un sinnúmero de urgencias vitales en las cuales se ve claramente amenazado el bienestar del paciente con repercusiones a corto, mediano y largo plazo e incluso la muerte. Es aquí donde se establece la importancia de contar con una red eficaz y suficiente que esté en la capacidad de dar respuesta a estas necesidades de atención. En el momento que un paciente ingresa a urgencias se observa la suficiencia de la red de servicios de atención en salud y se hace evidente la necesidad de garantizar la oportunidad y continuidad en la atención del servicio, donde se asegure al paciente una atención con calidad que minimice los riesgos de morir. Algunos pacientes ingresan a este servicio por múltiples causas y la atención se ve interrumpida en el momento que este requiere un mayor nivel de atención, donde el tiempo de referencia se hace largo y tanto el paciente como su familia deben esperar horas para recibir la atención especializada que requiere su situación clínica.

Una urgencia se considera como la atención inmediata que requiere un paciente en un periodo de tiempo corto donde se ve amenazado su bienestar físico, mental y/o emocional y el cual requiere una atención inmediata para minimizar el riesgo de presentar complicaciones a corto, mediano o largo plazo o incluso morir.

La atención de urgencia en muchas oportunidades va ligada a los servicios de referencia, el cual tiene como propósito garantizar la continuidad para la atención en salud cuando la institución que atiende inicialmente la urgencia no cuenta con los equipos médicos, diagnósticos, unidades o personal especializado para su atención, por esto, la referencia se considera el envío de pacientes o elementos de una institución prestadora de servicios de salud a otra institución que responda las necesidades de salud del paciente que demanda el servicio. El Decreto 4747 de 2007 establece que el paciente no supere 6 horas de espera desde su recepción hasta la estabilización y referencia, este proceso se define como importante teniendo en cuenta que si se realiza de manera oportuna y eficaz, disminuye el riesgo de morbimortalidad a corto, mediano y largo plazo.

La respuesta oportuna por parte de las EPS e IPS en cuanto al proceso de referencia se considera en la actualidad un problema teniendo en cuenta que en Colombia muchas instituciones prestadoras de servicios de salud no cumplen con 
el tiempo estándar para esta atención. Esto se manifiesta a través del informe reportado por la Superintendencia Nacional de Salud a través de su Circular Única correspondiente al II Semestre de 2011 el cual muestra los tiempos en oportunidad en referencia que oscilan entre 2.3 y 75 horas para el régimen contributivo con una media de 13.3 horas de espera; es claro el déficit en la red de prestadores de servicios que dificulta el traslado de los pacientes a un nivel superior de atención; de igual manera este dato no evidencia una adecuada gestión del riesgo que compromete la vida del paciente. Para el régimen subsidiado el tiempo es aún más largo con una espera mayor que oscila entre 1.0 y 83 horas con una media de 11.4, evidenciándose la larga espera de los usuarios para ser trasladados a un nivel superior de atención, lo que manifiesta un riesgo enorme de complicaciones a corto, mediano y largo plazo, y en otros casos el riesgo de morir en espera de satisfacer sus necesidades de atención en salud. (1)

Se realizó búsqueda en diferentes bases de datos como: PubMed, Journals, Lilacs, Proquest Health Managment, EBSCO, con términos Mesh como: Urgency, Opportunity, reference, referral , care. Las bases de datos no arrojaron estudios realizados sobre el tema tanto a nivel nacional como internacional, por lo cual se parte de la población que atiende la red pública del Distrito, la cual se distribuye en veinte Localidades con un total de 1.275.229, usuarios de acuerdo a la estadística presentada por el Ministerio de Salud y Protección Social, afiliados BDUA con corte a Abril de 2014 (2). Se proveen servicios a la población de las regiones Sur, Norte, Oriente y Occidente, teniéndose predominio de usuarios del régimen subsidiado, pero en ocasiones también atiende pacientes del régimen contributivo.

Con respecto al perfil de morbilidad, de acuerdo a datos entregados por la Secretaría de Salud Distrital, Salud a su hogar. Un modelo de Atención Primaria en Salud para garantizar el derecho a la salud en Bogotá, 2004, establece que en Bogotá se ha aumentado el número de pacientes con complicaciones en salud secundario al deterioro de enfermedades crónicas de base y sedentarismo, que sumado a un promedio de vida en aumento, complican el panorama en salud de los bogotanos. De acuerdo a la Encuesta Nacional de Salud 2007, dentro de los principales motivos de consulta en las instituciones de salud en la Capital, el de mayor prevalencia está relacionado con enfermedad física aguda o malestar de aparición reciente, seguido de enfermedad física o malestar de larga duración y en último lugar se establecen las consultas por atención preventiva. En cuanto a las principales causas de mortalidad, se registra que durante el año 2007 se distribuyeron de la siguiente manera: en primer lugar: enfermedades isquémicas del corazón, seguido de enfermedades cerebro vasculares y en tercer lugar enfermedades crónicas de vías respiratorias, con un total de 26.367 defunciones. 
La Secretaría Distrital de Salud registra 12.908 entidades prestadoras de salud, de las cuales 2.944 son Instituciones Prestadoras de Servicios de Salud, donde se manifiesta que el principal problema que se registra es la localización de estas, donde solo 155 son públicas y 2.579 son de carácter privado. El mayor número de IPS se ubica al norte, con una relación de 38 prestadores por cada 10.000, lo que dificulta en gran medida el acceso a la población de menor recurso económico. (3)

\section{JUSTIFICACIÓN}

La Constitución Política Colombiana en su artículo 49 señala que la atención en salud y el saneamiento ambiental son servicios públicos a cargo del Estado, también contempla el acceso a los servicios de promoción, protección y recuperación de la salud. Esta prestación debe estar enmarcada en los principios de eficiencia, universalidad y solidaridad.(4) De este modo, es claro afirmar que la salud es un servicio público a cargo del Estado y al cual los ciudadanos pueden acceder.

En Colombia el acceso a los servicios de salud está enmarcado a través de la Resolución número 5261 de 1994 "Por la cual se establece el Manual de Actividades, Intervenciones y Procedimientos del Plan Obligatorio de Salud en el Sistema General de Seguridad Social en Salud." El artículo $1^{\circ}$ de su libro I en el cual define el "Manual De Actividades, Intervenciones Y Procedimientos." Establece los Centros de Atención, y define que el Plan Obligatorio de Salud (POS) debe prestarse en todo el territorio Nacional mediante personas e instituciones ya sean de carácter público, privado o mixto que estén autorizados para prestar sus servicios el cual será definido bajo la responsabilidad de las Entidades Promotoras de Salud de acuerdo a la contratación con cada Institución Prestadora de Servicios (IPS). En su segundo artículo, menciona que dicha prestación del servicio estará sujeta al nivel de complejidad y a las IPS disponibles, en el caso que el usuario amerite un mayor nivel de atención de acuerdo a la complejidad de su patología, este servicio debe garantizarse a través de la red de prestadores de servicios. El acceso a los servicios siempre debe empezar por el primer nivel o el servicio de urgencias, en caso de requerir otro nivel de atención, el usuario debe ser remitido por un médico general. (5)

Lo anterior demuestra como los colombianos tienen derecho a la garantía de la prestación de los servicios de salud contemplados en el POS, en el cual debe existir continuidad del servicio de manera oportuna y eficaz, por lo que se debe minimizar al máximo las demoras en la atención, sobre todo si estas aumentan el riesgo de morbimortalidad, por esta razón, no es posible que en la actualidad existan procesos deficientes que permitan una prestación con demora y mala calidad, donde se permitan largos periodos de espera y donde los pacientes no tengan la certeza de la continuidad en su atención poniendo en riesgo sus vidas. 
Prueba de lo anterior lo demuestra el informe realizado por la Superintendencia Nacional de Salud a través de su Circular Única en el segundo periodo de 2011, donde se evidencian largos periodos de espera para que el paciente sea remitido a un mayor nivel de complejidad, en el régimen contributivo se evidencia un tiempo de espera para la referencia entre 2.3 y 75 horas, con una media de 13.3 horas. Para el régimen subsidiado el tiempo de espera para la referencia es aún más largo, este oscila entre 1.0 y 83 horas con una media de 11.4. (6) Es claro el déficit en la red de prestadores de servicios que dificulta el traslado de los pacientes a un nivel superior de atención; de igual manera este dato no evidencia una adecuada gestión del riesgo que compromete la vida del paciente. Con base a lo anterior, es evidente la falta de cumplimiento de los principios de integralidad, complementariedad y calidad establecidos por la Comisión de Regulación en Salud (CRES) a través del acuerdo 029 de 2011(4) en el cual si un paciente no es trasladado a un mayor nivel de atención en el momento oportuno aumenta el riesgo de afectar su integralidad física, emocional, psicosocial, entre otros.

La prestación de los servicios en ejercicio del cumplimiento del POS, pone de manifiesto la necesidad de dar cumplimiento al Decreto 1011 de 2006 el cual establece el "Sistema Obligatorio de Garantía de Calidad de la Atención en el Sistema General de Seguridad Social en Salud." (7)

Mediante la revisión de casos reportados y gestionados en la Personería de Bogotá, se evidencian pacientes con dificultad en la asignación de la unidad médica especializada que requiere para su tratamiento y rehabilitación, hecho que se exacerba bajo el argumento de algunas EPS sustentado en la red de prestadores, lo cual limita la oportunidad en la atención, lo que ha llevado a que se solicite con base a la los diferentes argumentos jurídicos la prioridad en el Derecho a la vida. Para algunos pacientes la pronta intervención de la Personería de Bogotá ha permitido lograr el traslado exitoso, para otros, este momento llega demasiado tarde. Los familiares manifiestan a la Personería de Bogotá su larga espera antes de solicitar ayuda y desafortunadamente en algunos casos cuando se inicia el proceso de búsqueda de la unidad, el paciente fallece por complicaciones del proceso de atención.

\section{OBJETIVOS}

\section{OBJETIVO GENERAL}

Identificar la oportunidad de referencia en los servicios de urgencias para los hospitales de la red pública del Distrito

\section{OBJETIVOS ESPECÍFICOS}

- Determinar número de referencias en urgencias vitales 
- Estimar oportunidad en la referencia en los servicios de urgencias en el Distrito Capital

- Determinar el número de pacientes que fallecen en la espera de referencia en el servicio de urgencias.

- Analizar tiempos de respuesta entre la solicitud de referencia y el egreso del paciente.

\section{MARCO TEÓRICO}

Referencia y Contrarreferencia: Conjunto de procesos, procedimientos y actividades técnicos y administrativos que permiten prestar adecuadamente los servicios de salud a los pacientes, garantizando la calidad, accesibilidad, oportunidad, continuidad e integralidad de los servicios, en función de la organización de la red de prestación de servicios definida por la entidad responsable del pago. (8)

Referencia: Envío de pacientes o elementos de ayuda diagnóstica por parte de un prestador de servicios de salud, a otro prestador para atención o complementación diagnóstica que, de acuerdo con el nivel de resolución, de respuesta a las necesidades de salud. (8)

Contrarreferencia: Respuesta que el prestador de servicios de salud receptor de la referencia, da al prestador que remitió. (8)

Urgencia. "Es la alteración de la integridad física y/o mental de una person a, causada por un trauma o por una enfermedad de cualquier etiología que genere una demanda de atención médica inmediata y efectiva, tendiente a disminuír los riesgos de in validez y muerte." (9)

Atención inicial de urgencia. "todas las acciones realizadas a una persona con patología de urgencia y que tiendan a estabilizarla en sus sign os vitales, realizar un diagnóstico de impresión y definirle el destino inmediato, tomando como base el nivel de atención y el grado de complejidad de la entidad que realiza la atención inicial de urgencia, al tener de los principios éticos y las normas que determinan las acciones y el comportamiento del personal de salud." (9)

Atención de urgencia. "Es el conjunto de acciones realizadas por un equi po de salud debidamente capacitado y con los recursos materiales necesarios para satis facer la demanda de atención generada por las urgencias." (9)

Niveles de Complejidad: Se sustituye el concepto: Nivel I, II y III por el actual: bajo nivel que sustituye el término I nivel, mediano nivel que sustituye el término II nivel y alto nivel que sustituye el término III nivel. 
A continuación se citan algunos aspectos normativos que favorecen el concepto de oportunidad y Derecho a la salud.

Partiendo de La Ley de Leyes se cita la Constitución Política de Colombia título II de los derechos, las garantías y los deberes artículos. 48, 49, y 50. Donde se otorga una responsabilidad importante al estado como garante del cumplimiento al acceso a la Seguridad Social y es por esto, que el Artículo 48 establece: "La Seguridad Social es un servicio público de carácter obligatorio que se prestará bajo la dirección, coordinación y control del Estado, en sujeción a los principios de eficiencia, universalidad y solidaridad, en los términos que establezca la Ley." (10) "Se garantiza a todos los habitantes el derecho irrenunciable a la Seguridad Social. El Estado, con la participación de los particulares, ampliará progresivamente la cobertura de la Seguridad Social que comprenderá la prestación de los servicios en la forma que determine la Ley." (10) El Artículo 49 menciona: "La atención de la Salud y el saneamiento ambiental son servicios públicos a cargo del Estado. Se garantiza a todas las personas el acceso a los servicios de promoción, protección y recuperación de la Salud." (10) Por último el Artículo 50 manifiesta: "Corresponde al Estado organizar, dirigir y reglamentar la prestación de servicios de salud a los habitantes y de saneamiento ambiental conforme a los principios de eficiencia, universalidad y solidaridad." (10)

No obstante la ley 100 de 1993, estipuló algunas características importantes que deben caracterizar a un servicio de salud con calidad, (11) entre algunas se mencionan:

- Accesibilidad

- Oportunidad

- Seguridad

- Idoneidad profesional

- Suficiencia de recursos

- Eficiencia-Eficacia

- Integralidad

- Atención humanizada

- Satisfacción del usuario

- Estándares aceptados

Hablando de calidad, es importante mencionar el Decreto 1011 de 2006 el cual establece el Sistema Obligatorio de Garantía de Calidad De La Atención En Salud S.O.G.C.S, donde se entiende como la provisión de servicios de salud a los usuarios individuales y colectivos de manera ACCESIBLE y EQUITATIVA, a través de un nivel profesional óptimo, teniendo en cuenta el balance entre BENEFICIOS, RIESGOS y COSTOS, con el propósito de lograr la adhesión y SATISFACCION de dichos usuarios. (12). Se mencionan principios como: accesibilidad, pertinencia, oportunidad, seguridad y continuidad. 
El Decreto 4747 de 2007 Menciona la relevancia del acceso oportuno a los servicios de salud, eliminando barreras administrativas en su Artículo 11 establece: "En la verificación de derechos de los usuarios no podrán exigirse al usuario copias, fotocopias o autenticaciones de ningún documento." (13) El Parágrafo 1 de la misma norma establece: "El procedimiento de verificación de derechos será posterior a la selección y clasificación del paciente, "triage" y no podrá ser causa bajo ninguna circunstancia para posponer la atención inicial de urgencias. "(14)

En términos de tiempos de atención, de acuerdo al Artículo 14 del mismo Decreto: se establece la responsabilidad de las EPS y se estipula: "La respuesta a la solicitud de autorización de servicios posteriores a la atención de urgencias, deberá darse por parte de la entidad Responsable del pago, dentro de los siguientes términos:"

- Para atención subsiguiente a la atención inicial de urgencias: Dentro de las dos (2) horas siguientes al recibo de la solicitud.

- Para atención de servicios adicionales: Dentro de las seis (6) horas siguientes al recibo de la solicitud. (15)

El Artículo 17 otorga: “El diseño, organización, documentación y operación del proceso de referencia es obligación de las entidades responsables del pago de servicios de salud, quienes deberán disponer de una red de prestadores de servicios de salud que garanticen la disponibilidad y suficiencia de los servicios en todos los niveles de complejidad a su cargo, así como la disponibilidad de la red de transporte y comunicaciones." (16)

"Con el fin de garantizar la calidad, continuidad e integralidad en la atención, es obligación de las entidades responsables del pago de servicios de salud la consecución de institución prestadora de servicios de salud receptora que garantice los recursos humanos, físicos o tecnológicos así como los insumos y medicamentos requeridos para la atención de pacientes." (16)

La ley 1438 de 2011 en el título VI: de la prestación de servicios de salud capítulo I en su Artículo 53 menciona la prohibición de limitaciones al acceso. "Están prohibidos aquellos mecanismos de pago, de contratación de servicios, acuerdos o políticas internas que limiten el acceso al servicio de salud o que restrinjan su continuidad, oportunidad, calidad o que propicien la fragmentación en la atención de los usuarios." (17)

La Resolución 5521 de 2013 define El Plan Obligatorio de Salud como "el conjunto de tecnologías en salud descritas en el presente acto administrativo, que determina a qué tiene derecho, en caso de necesitarlo, todo afiliado al Sistema General de Seguridad Social en Salud - SGSSS-. Se constituye en un instrumento para que las Entidades Promotoras de Salud -EPS garanticen el acceso a las tecnologías en salud en las condiciones previstas en este acto administrativo. El artículo 9. Habla de la garantía de acceso a los servicios de salud donde "Las Entidades Promotoras de Salud deberán garantizar a los afiliados al SGSSS el acceso efectivo a las 
tecnologías en salud incluidas en el presente acto administrativo, a través de su red de prestadores de servicios de salud."(18)

Artículo 97. ATENCIÓN DE URGENCIAS. El Plan Obligatorio de Salud cubre las tecnologías necesarias para la atención de urgencias, siendo obligatoria la cobertura de la atención inicial de urgencias por parte de la Entidad Promotora de Salud al paciente que haya demandado los servicios, incluyendo la oportuna y adecuada remisión cuando no cuente con las tecnologías necesarias para la atención del caso. (18)

\section{METODOLOGÍA}

A continuación se establece la metodología empleada para el estudio cuantitativo de carácter descriptivo, al cual pertenece la presente investigación.

Inicialmente, se establece que toda la información obtenida por medio de la Personería de Bogotá, será de manejo exclusivo para la entidad y en el cual de acuerdo al contrato de los funcionarios está prohibida la reproducción de la misma, independientemente del ámbito.

Por lo anterior se manejarán los nombres de las instituciones que reportan, teniendo en cuenta que ésta información será de manejo institucional y busca generar estrategias que mejoren la restitución del derecho a la salud, como eje central del grupo de Personería para la Asistencia en Salud, -PAS-.

Se aclaró a los hospitales mediante las visitas administrativas y/o telefónicamente (instituciones que se comunicaron a solicitar aclaración de algunos puntos de la solicitud) que ésta investigación no era de carácter evaluativo y por el contrario los datos reportados permitirían revisar la oportunidad en el tema de interés, con el propósito de mejorar el derecho a la salud.

\section{LIMITANTES DEL ESTUDIO}

Puede existir subregistro de datos de los hospitales en el reporte por el temor de las instituciones a la evaluación, por el hecho de ser un ente de control quien solicite la información. Sin embargo cuando se visitaron las instituciones

De los 22 hospitales de la red Pública se realizó la solicitud a 20 E.S.E.s (ver Listado 1) de la red pública del Distrito la información que se presenta en la Caja 1. Como criterio de inclusión, los hospitales debían contar con el servicio de urgencias. Los 22 cuentan con este servicio. Se excluyó Bosa y Usaquén por dificultad en la entrega de correspondencia.

Las instituciones requeridas constituyen una muestra representativa que incluye los tres niveles de complejidad que maneja el Distrito: bajo, mediano y alto, con el propósito de analizar el comportamiento de la oferta y demanda de referencias en 
el servicio de urgencias y al mismo tiempo, el registro de estos datos de interés por parte de las IPS. Se realizó la solicitud tanto al hospital como a sus respectivos Centros de Atención Inmediata (CAMIs).

La información fue solicitada a los Gerentes de las E.S.E.s mediante oficio radicado en el grupo de Personería para la Asistencia en Salud, a través de correo certificado (Ver Anexo 1).

CAJA 1. INFORMACIÓN REQUERIDA A LAS INSTITUCIONES DE LA RED PÚBLICA

- Número de referencias solicitadas en el servicio de urgencias en el hospital cualquier Triage.

- Número de referencias en urgencias vitales.

- Número de referencias de Triage 1 por servicios requeridos.

- Número de referencias atendidas en el servicio de urgencias en los turnos.

- Número de servicios tercerizados contratados por especialidad en la institución.

- Número de pacientes que fallecen sin recibir la referencia solicitada.

- Tiempo máximo, mínimo y promedio entre la solicitud de referencia y el egreso de la institución.

- Oferta y demanda de referencias en urgencias en la institución.

- Talento humano en el servicio de urgencias por turno.

- Contrarreferencias efectivas por Triage.

- Tiempo máximo, mínimo y promedio de solución del servicio de contrarreferencia

- Número de referencias no atendidas oportunamente por no contar con el servicio requerido.

- Coordinador de urgencias por turno.

Listado 1. Instituciones requeridas de información

1. ospital El Tunal

2. Hospital La Victoria

3. Hospital de Kennedy

4. Hospital Santa Clara

5. Hospital Simón Bolívar

6. Hospital Tunjuelito

7. Hospital Fontibón

8. Hospital San Blas

9. Hospital Centro Oriente

10. Hospital Engativá 
11. Hospital Meissen

12. Hospital del Sur

13. Hospital Pablo VI de Bosa

14. Hospital Chapinero

15. Hospital Vista Hermosa

16. Hospital Rafael Uribe Uribe

17. Hospital Nazareth

18. Hospital San Cristóbal

19. Hospital de Suba

20. Hospital de Usme

Luego de recibir el $100 \%$ de los reportes de los hospitales a los que se les solicitó la información, se creó una base de datos en Excel ${ }^{\circledR}$, segmentándola por cada año de medición (2012 / 2013 / enero a julio de 2014) con las variables solicitadas.

Se realizó el filtro por nivel de complejidad, y se procedió a analizar en primer lugar hospitales de bajo nivel de complejidad, en segundo lugar de mediano nivel y en tercer lugar de alto nivel.

Se calculó el porcentaje de muestra para medición mediante regla de tres, teniendo en cuenta el número de hospitales por nivel de complejidad solicitados, como se muestra en la Caja 2.

\section{CAJA 2. CÁlCULO DEL PORCENTAJE DE LA MUESTRA PARA LA MEDICIÓN}

Número de hospitales que reportan la información solicitada $\times 100$

Total de hospitales a quienes se les solicitó la información

Se aclara que los resultados son proporciones con base al reporte obtenido del porcentaje de hospitales que reportaron información apta para ser medida, cuya información responde la solicitud y permite medición y análisis.

Cada variable se analizó de manera individual, citando el hospital y lo que reportó. Posteriormente se agruparon los datos para presentar los totales y porcentajes de acuerdo a lo que se estaba midiendo, al final de cada variable se presenta un análisis por año y finalmente mediante líneas se grafica el comportamiento de la variable de medición para los años 2012 / 2013 / enero a julio 2014 con el respectivo análisis general y por año, citando hallazgos importantes como: hospitales que no reportan, incongruencia de datos o datos no adecuados para medición por no responder de manera explícita la solicitud, entre otros. 
HOSPITALES ANALIZADOS

Se realizó solicitud de información para análisis a los siguientes hospitales de la Red.

- BAJO NIVEL DE COMPLEJIDAD: De los 9 Hospitales de bajo nivel, se hizo la solicitud a 8, (Se incluyeron los respectivos CAMls) de los cuales, el 100\% reportó la información.(Se excluyó Usaquén)

- MEDIANO NIVEL DE COMPLEJIDAD: De los 8 Hospitales de mediano nivel, se hizo la solicitud a 7, (Se incluyeron los respectivos CAMls) de los cuales, el 100\% reportó la información.(Se excluyó Bosa)

- ALTO NIVEL DE COMPLEJIDAD: De los 5 Hospitales de alto nivel de complejidad, se hizo la solicitud a los 5 de los cuales el $100 \%$ reportó la información.

\begin{tabular}{|l|l|l|l|}
\hline $\begin{array}{l}\text { Nivel } \\
\text { complejidad }\end{array}$ & Cantidad en la red & $\begin{array}{l}\text { Cantidad } \\
\text { solicitados }\end{array}$ & $\begin{array}{l}\text { Porcentaje reporte } \\
\text { recibido }\end{array}$ \\
\hline BAJO & 9 & 8 & $100 \%$ \\
\hline MEDIANO & 8 & 7 & $100 \%$ \\
\hline ALTO & 5 & 5 & $100 \%$ \\
\hline
\end{tabular}

POBLACIÓN QUE ATIENDEN LOS HOSPITALES DE LA RED PÚBLICA

La red pública presta sus servicios de salud a las veinte (20) Localidades del Distrito con un total de 1.275.229 usuarios de acuerdo a la estadística presentada por el Ministerio de Salud y Protección Social, afiliados BDUA con corte a Abril de 2014. (19) Se proveen servicios a la población de las regiones Sur, Norte, Oriente y Occidente, teniéndose predominio de usuarios del régimen subsidiado, pero en ocasiones también atiende pacientes del régimen contributivo.

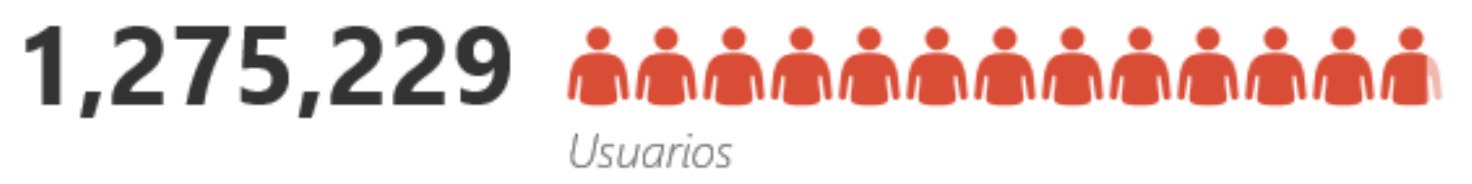




\section{RESULTADOS}

\section{HOSPITALES BAJO NIVEL DE COMPLEJIDAD}

\begin{tabular}{|l|l|}
\hline NOMBRE DE LA E.S.E. & \multicolumn{1}{|c|}{ CAMIS Y/O HOSPITALES } \\
\hline \multirow{4}{*}{ HOSPITAL VISTA HERMOSA } & HOSPITAL VISTA HERMOSA \\
\cline { 2 - 2 } & CAMI CANDELARIA \\
\cline { 2 - 2 } & CAMI JERUSALEN \\
\cline { 2 - 2 } & CAMI VISTA HERMOSA \\
\cline { 2 - 2 } & CAMI MANUELA BELTRÁN \\
\hline
\end{tabular}

\begin{tabular}{|l|l|}
\hline \multirow{2}{*}{ HOSPITAL CHAPINERO } & HOSPITAL CHAPINERO \\
\cline { 2 - 2 } & CAMI CHAPINERO \\
\hline
\end{tabular}

\begin{tabular}{|l|l|}
\hline \multirow{4}{*}{$\begin{array}{c}\text { HOSPITAL RAFAEL URIBE } \\
\text { URIBE }\end{array}$} & HOSPITAL RAFAEL URIBE URIBE \\
\cline { 2 - 2 } & CAMI CHIRCALES \\
\cline { 2 - 2 } & CAMI DIANA TURBAY \\
\cline { 2 - 2 } & CAMI OLAYA \\
\hline
\end{tabular}

\begin{tabular}{|l|l|}
\hline \multirow{2}{*}{ HOSPITAL SAN CRISTOBAL } & HOSPITAL SAN CRISTÓBAL \\
\cline { 2 - 2 } & CAMI ALTAMIRA \\
\hline
\end{tabular}

\begin{tabular}{|l|l|}
\hline \multirow{2}{*}{ HOSPITAL NAZARET } & HOSPITAL NAZARET \\
\cline { 2 - 2 } & CAMI NAZARET \\
\hline
\end{tabular}

\begin{tabular}{|l|l|}
\hline HOSPITAL PABLO VI BOSA & HOSPITAL PABLO VI BOSA \\
\hline
\end{tabular}

\begin{tabular}{|l|l|}
\hline \multirow{2}{*}{ HOSPITAL DEL SUR } & HOSPITAL DEL SUR \\
\cline { 2 - 2 } & CAMI PATIO BONITO \\
\cline { 2 - 2 } & CAMI TRINIDAD GALÁN \\
\hline
\end{tabular}

\begin{tabular}{|l|l|}
\hline \multirow{2}{*}{ HOSPITAL DE USME } & HOSPITAL DE USME \\
\cline { 2 - 2 } & CAMI SANTA LIBRADA \\
\cline { 2 - 2 } & CAMI USME \\
\hline
\end{tabular}

De los 9 Hospitales de primer nivel, se hizo la solicitud a 8, de los cuales el 100\% reportó la información.

NUMERO DE REFERENCIAS SOLICITADAS EN EL SERVICIO DE URGENCIAS EN EL HOSPITAL CUALQUIER TRIAGE VS NUMERO DE REFERENCIAS EN URGENCIAS VITALES EN LOS AÑOS 2012, 2013 Y DE ENERO A JULIO DE 2014 


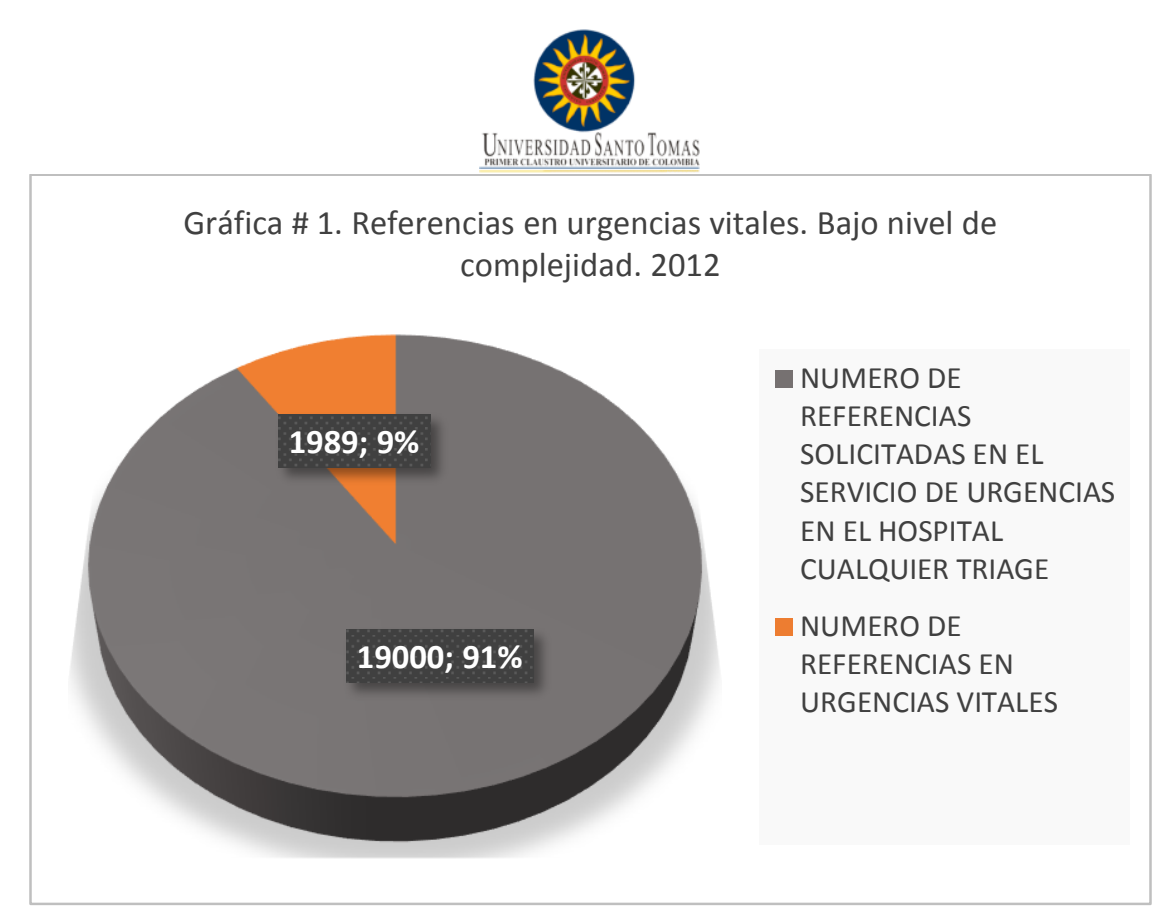

Para el año 2012 en promedio, del 100\% de las referencias solicitadas en urgencias en los hospitales de bajo nivel de complejidad, el $9 \%$ correspondió a urgencias vitales.

\section{NÚMERO DE REFERENCIAS EN URGENCIAS VITALES PARA EL AÑO 2013}

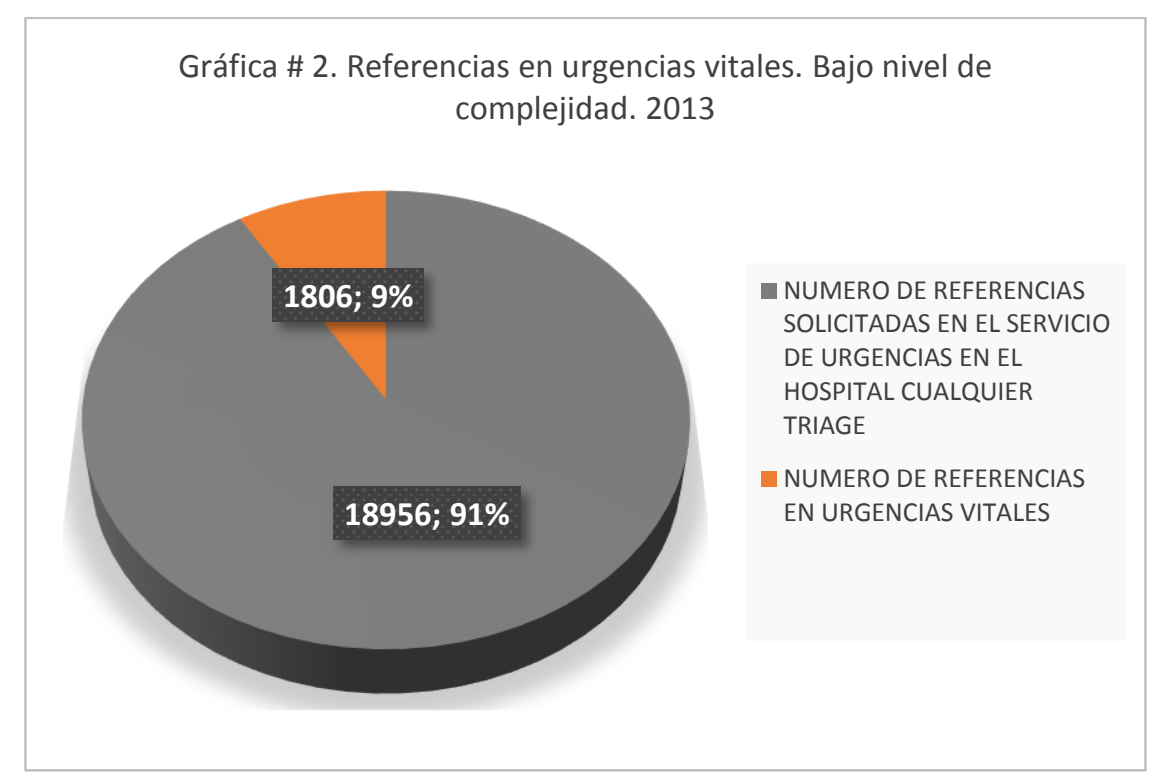

Para el año 2013, en promedio, del 100\% de las referencias solicitadas en urgencias en los hospitales de baja complejidad, el 9\% correspondió a urgencias vitales. 


\section{NÚMERO DE REFERENCIAS EN URGENCIAS VITALES DE ENERO A JULIO DE 2014}

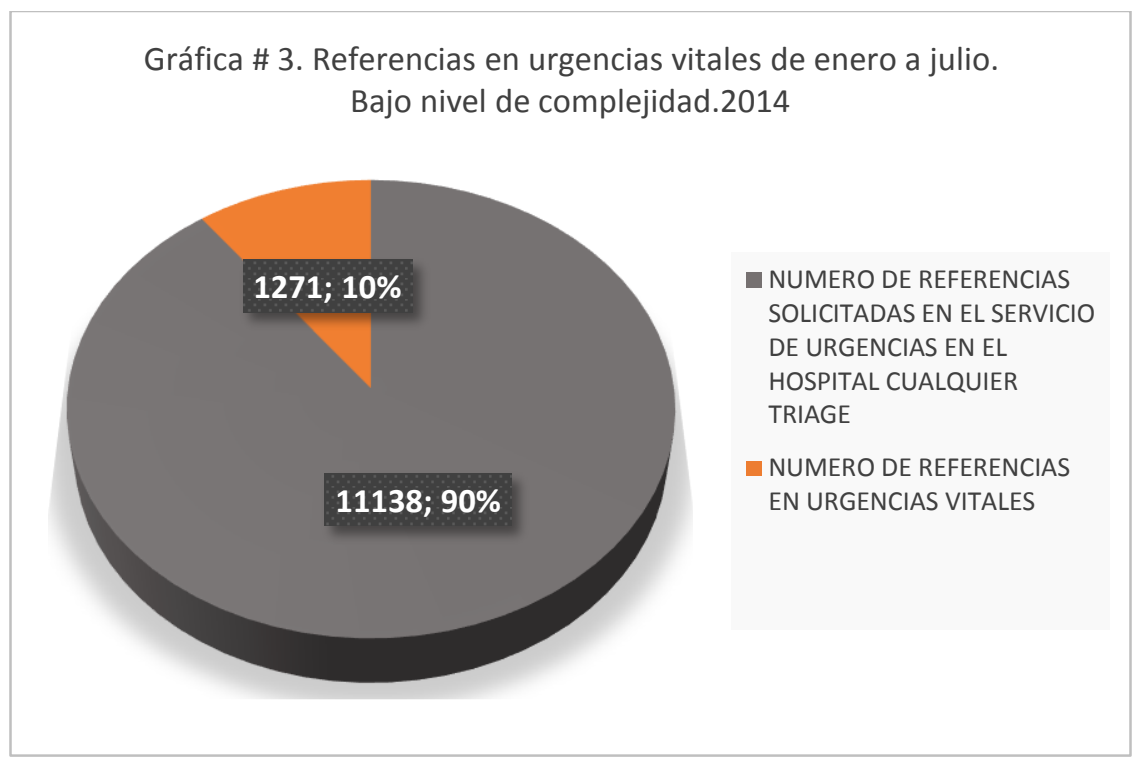

Para el periodo de enero a julio de 2014 en promedio, del 100\% de las referencias solicitadas en urgencias en los hospitales de bajo nivel de complejidad el $10 \%$ correspondió a urgencias vitales.

NÚMERO DE PACIENTES QUE FALLECEN SIN RECIBIR LA REFERENCIA SOLICITADA

NÚMERO DE PACIENTES QUE FALLECEN SIN RECIBIR LA REFERENCIA SOLICITADA 2012

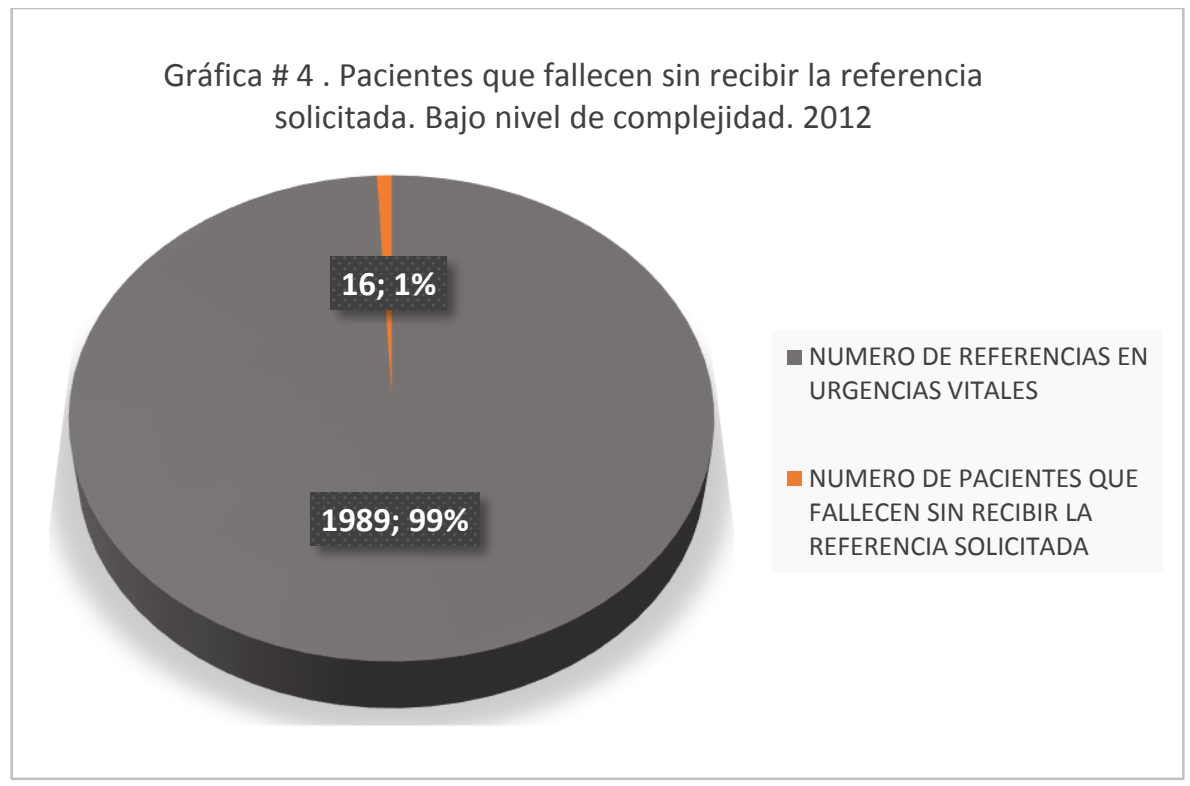


Del total de referencias solicitadas en urgencias vitales en el año 2012, el $1 \%$ fallece sin recibir la referencia solicitada.

\section{NÚMERO DE PACIENTES QUE FALLECEN SIN RECIBIR LA REFERENCIA SOLICITADA 2013}

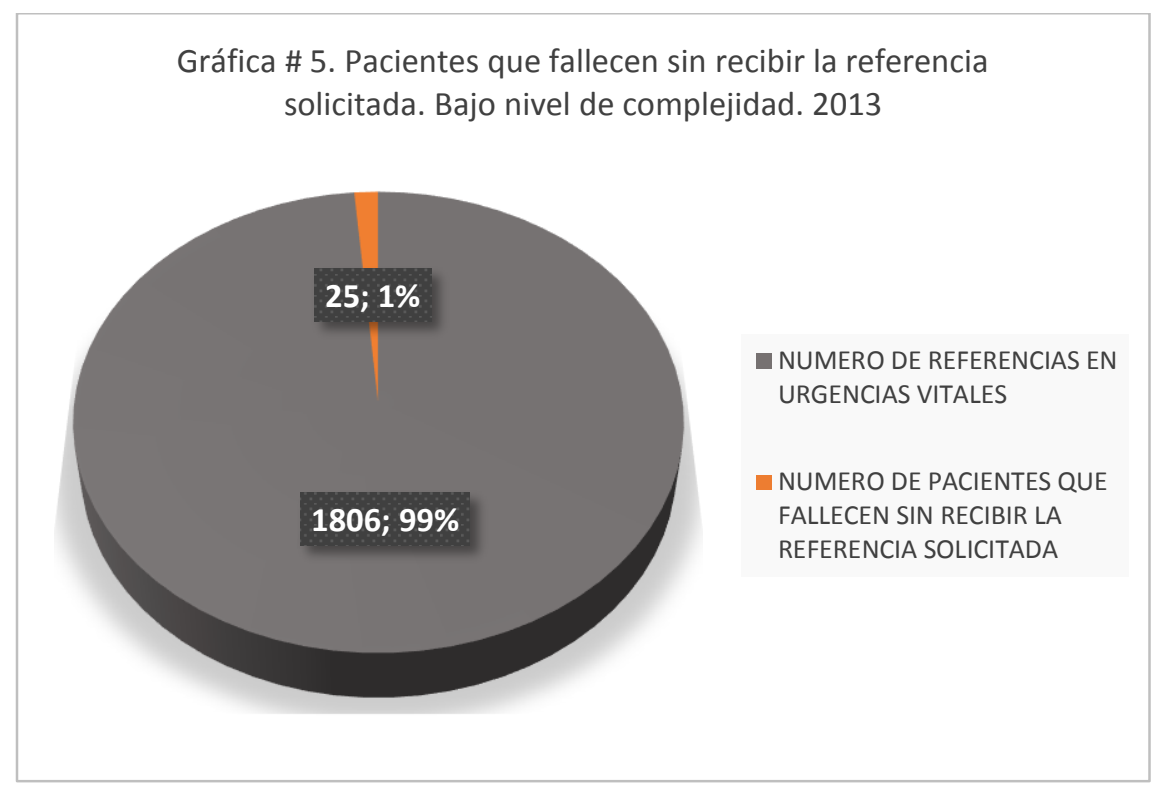

Del total de referencias solicitadas en urgencias vitales en el año 2013, el $1 \%$ fallece sin recibir la referencia solicitada.

\section{NÚMERO DE PACIENTES QUE FALLECEN SIN RECIBIR LA REFERENCIA SOLICITADA DE ENERO A JULIO DE 2014}

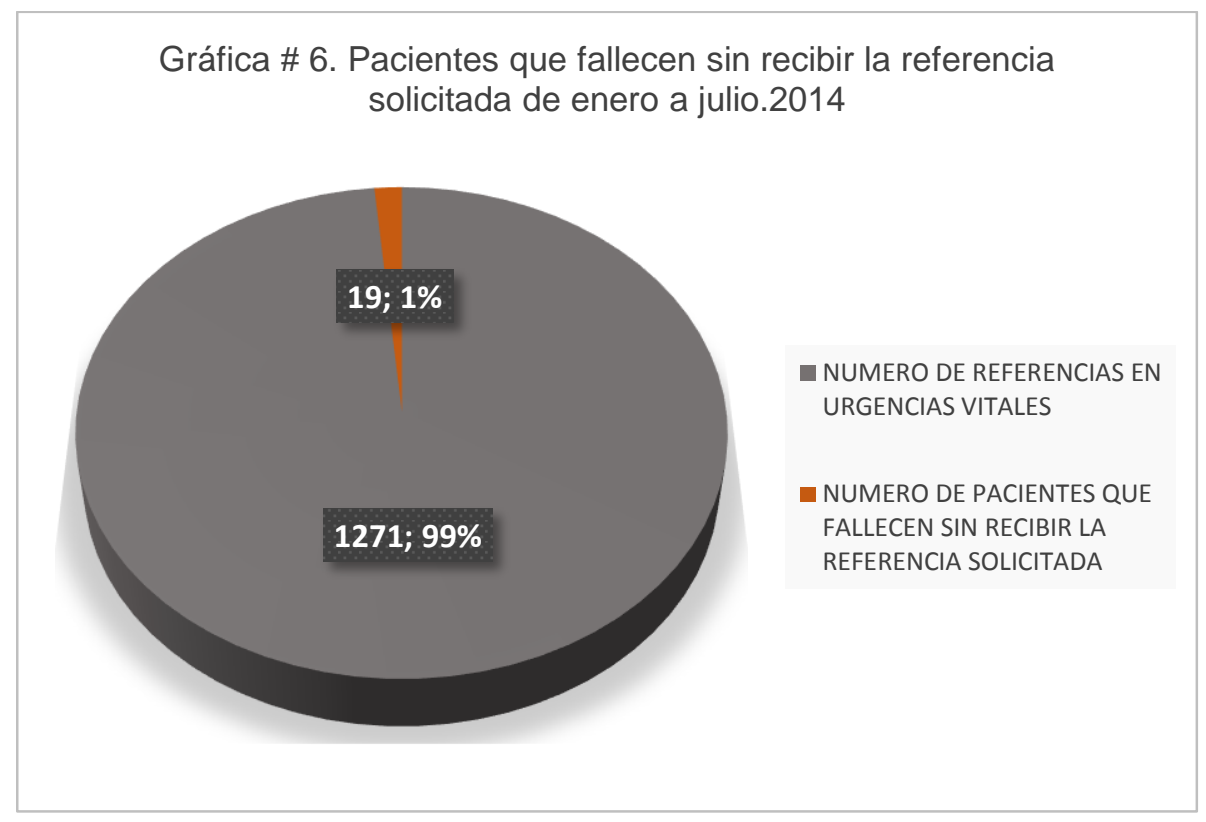


Del total de referencias solicitadas en urgencias vitales de enero a julio de 2014, el $1 \%$ fallece sin recibir la referencia solicitada.

El análisis revela que en el periodo analizado (2012/2013 y enero a julio de 2014), fallecieron 60 personas en espera de la remisión, dato que se puede dejar a consideración teniendo en cuenta que Hospitales como Vista Hermosa, y Usme reportaron 0 en sus 3 periodos y Nazareth reportó $1 \mathrm{El}$ mayor número de pacientes fallecidos está reportado por el Hospital Pablo VI de Bosa con 28 casos, seguido del Hospital del Sur con 13, San Cristóbal con 9 y Rafael Uribe Uribe con 9.

¿Es posible que Vista Hermosa y Usme el cual agrupan 7 CAMls con un perfil poblacional de estrato socioeconómico 1-2 con picos de urgencias vitales los fines de semana, fechas de pago y festividades entre otros, tenga un equivalente de 0 en 2 años y medio?

Este dato indicaría que existe una gestión eficaz en el proceso de referencia y contrarreferencia, hecho que debe ser sujeto de seguimiento teniendo en cuenta las consideraciones expuestas anteriormente. Vale la pena revisar si existe un subregistro o la falta de un sistema de información aplicado que sea eficaz en el reporte de datos reales.

\section{PROMEDIO EN HORAS ENTRE LA SOLICITUD DE REFERENCIA Y EL}

\section{EGRESO DE LA INSTITUCION}

\section{PROMEDIO EN HORAS ENTRE LA SOLICITUD DE REFERENCIA Y EL EGRESO DE LA INSTITUCION 2012, 2013 Y DE ENERO A JULIO DE 2014}

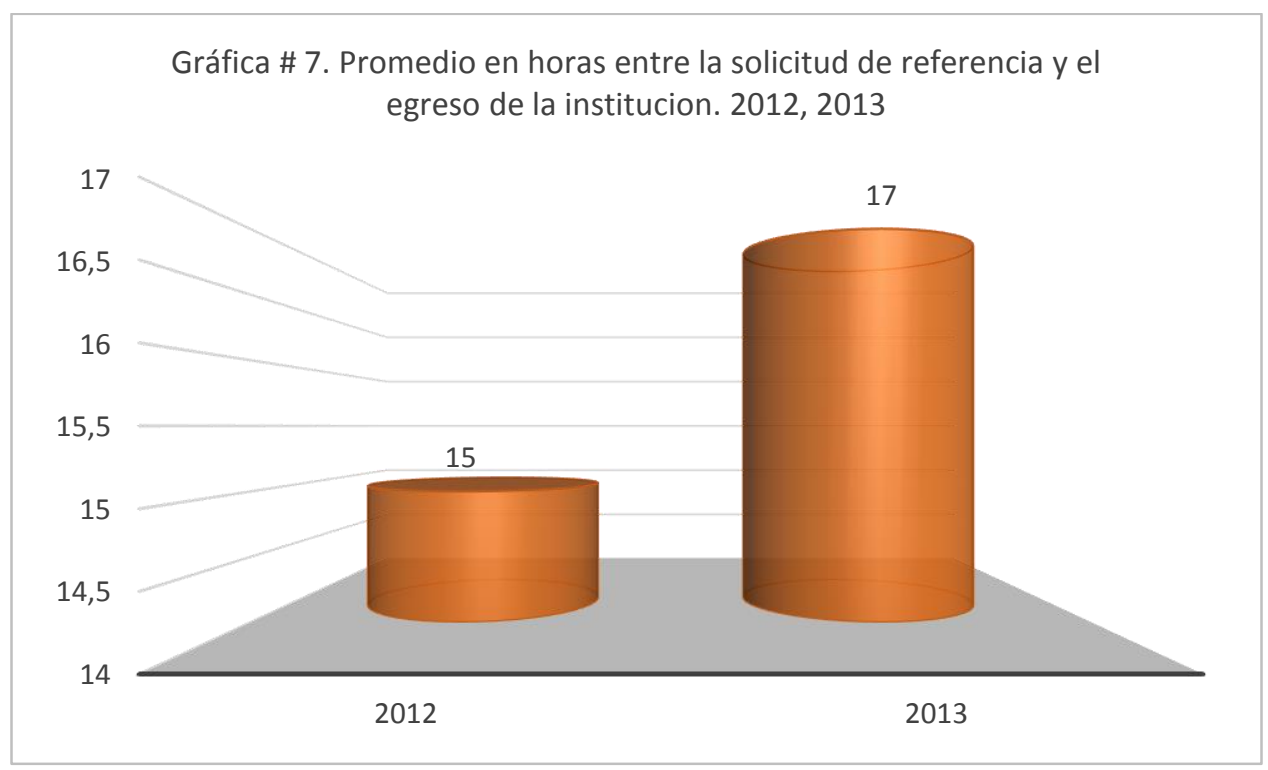


De acuerdo al reporte realizado por los hospitales de bajo nivel de complejidad, se evidencia que para el año 2012 el promedio estuvo en 15.4 horas desde la solicitud de referencia hasta el traslado del paciente a un mayor nivel de complejidad. El hospital que reporta el mayor tiempo de espera en horas es el Hospital Pablo VI de Bosa con 24,5 horas, seguido del hospital de Usme con 24 horas y San Cristóbal con 23 horas. Los promedios más bajos se evidencian en el hospital del Sur con 4.4 horas, seguido del hospital de Chapinero con 2.5. El Hospital Rafael Uribe reporta un dato que no es claro para su medición, Nazareth no reporta dato.

Para el año 2013, el promedio estuvo en 17.1 horas. El hospital con el mayor promedio de espera lo presentó el hospital San Cristóbal con 26 horas, seguido de Vista Hermosa con 22 horas, Pablo VI con 20.1 horas, Usme con 18 horas. El menor promedio de espera reportado lo hace el hospital del Sur con 6.8 horas seguido de Chapinero con 2.5 horas. El hospital Rafael Uribe Uribe no reporta un dato claro que permita su medición, Nazareth no reporta dato.

Para el año 2014, el promedio de enero a julio estuvo en 15.3 horas. El Hospital con el mayor promedio de espera fue Vista Hermosa con 34 horas, seguido de San Cristóbal con 20 horas, Usme con 12 horas y Pablo VI de Bosa con 8 horas. Los hospitales con menor promedio fueron hospital del Sur con 7.9 horas y Chapinero con 2.5 horas.

\section{OFERTA DE REFERENCIAS EN URGENCIAS EN LA INSTITUCIÓN \\ OFERTA DE REFERENCIAS EN URGENCIAS EN LA INSTITUCION 2012, 2013 Y DE ENERO A JULIO DE 2014}

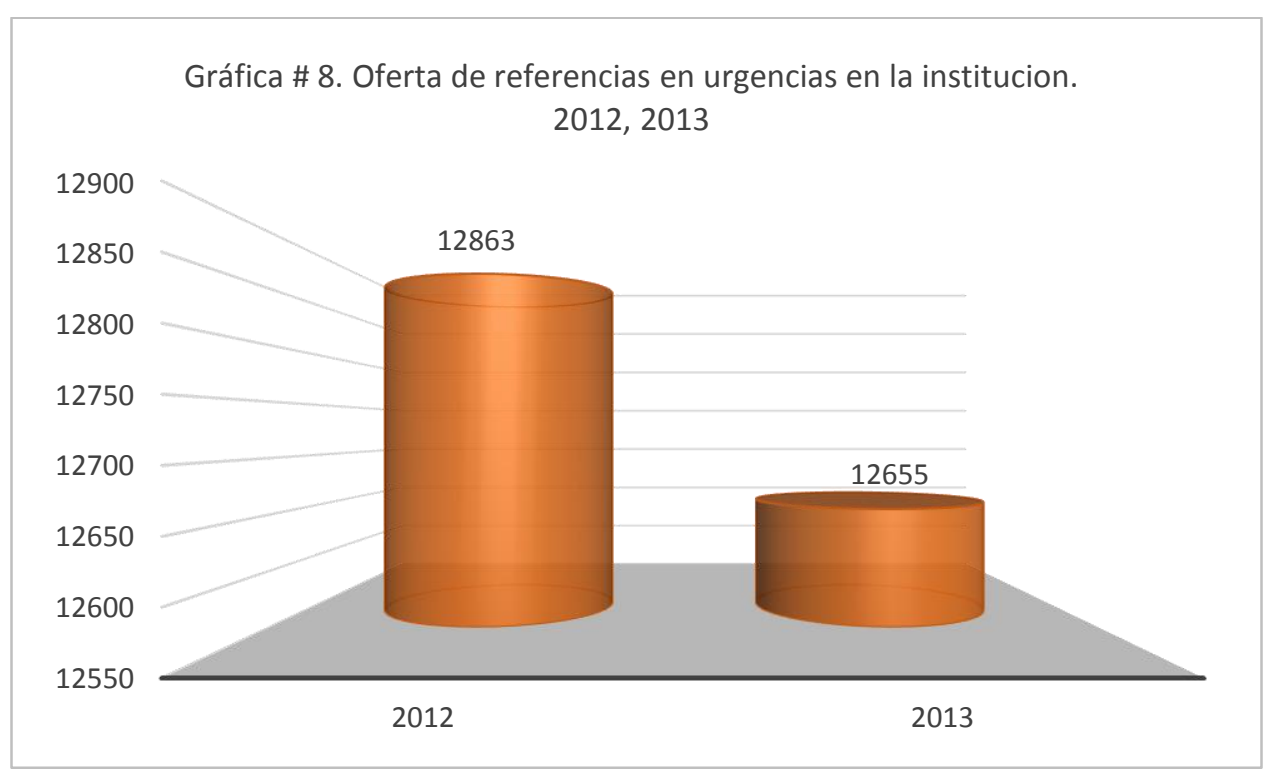




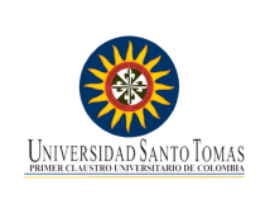

Inicialmente se aclara que este nivel de complejidad no realiza demanda de referencias por el nivel de complejidad al que pertenecen.

Para el año 2012, se reportaron un total de 8409 referencias solicitadas. El hospital Vista Hermosa reporta 4961 referencias solicitadas, Chapinero reporta los porcentajes de solicitud así: Ginecología: 32\% Medicina Interna: 22\% Cirugía General: 21\% Pediatría: 16\% Ortopedia: 4\% Psiquiatría: 2\% Otras: 3\%. Usme reporta 3448 referencias, el mayor número de estas se evidencia para otras especialidades con 978, seguido de Pediatría con 606, Ginecología con 578, ortopedia con 518, cirugía general con 388 , Medicina Interna con 380 . Pablo VI de Bosa reporta un total de 4454 solicitudes. La mayor demanda de referencias es para Ginecoobstetricia con 1489, seguido de Pediatría con 899, Medicina Interna con 544, Cirugía General con 521 y Ortopedia y Traumatología con 332, para las demás especialidades médicas oscila entre 1 y 110 solicitudes. San Cristóbal, Rafael Uribe Uribe, hospital del Sur y Nazareth no reportan dato.

Para el año 2013, hubo un total de 7949 referencias solicitadas. Vista Hermosa con 4316 solicitudes, Chapinero reporta los porcentajes de solicitud así: Ginecología: 32\% Medicina Interna: 22\% Cirugía General: 21\% Pediatría: 16\% Ortopedia: 4\% Psiquiatría: $2 \%$ otras: $3 \%$. Usme reporta un total de 3633 de referencias soicitadas, el mayor número de estas se evidencia para otras especialidades con 2707, seguido de Ortopedia con 337, Cirugía General con 238, Pediatría con 164, Ginecología con 105 y Medicina Interna con 81. El Hospital Pablo VI de Bosa reporta un total de 4706 solicitudes. La mayor demanda de referencias es para Ginecobstetricia con 1381, Pediatría con 870, Medicina interna con 738, Cirugía general con 557 y Ortopedia y traumatología con 364 , las demás especialidades médicas oscilan entre 1 y 135. San Cristóbal, Rafael Uribe Uribe, hospital del Sur y Nazareth no reportan dato.

Para el periodo de enero a julio de 2014, hubo un total de 6982 referencias solicitadas. Vista Hermosa con 2323. Chapinero reporta los porcentajes de solicitud así: Ginecología: 32\%, Medicina Interna: 22\%, Cirugía General: 21\%, Pediatría: 16\%, Ortopedia: 4\%, Psiquiatría: 2\%, otras: 3\%. Usme reporta un total de 1809 referencias solicitadas. El mayor número de estas se evidencia para otras especialidades con 1416 solicitudes, seguido de Cirugía General con 197, Ortopedia con 140, Medicina Interna con 26, Ginecología con 22 y Pediatría con 8. Pablo VI de Bosa reporta un total de 2850 solicitudes. La mayor solicitud de referencias es para Ginecobstetricia con 674 solicitudes seguido de Pediatría con 640, Medicina Interna con 531 y Cirugía general con 331, las demás especialidades médicas oscilan entre 1 y 188. San Cristóbal, Rafael Uribe Uribe, hospital del Sur y Nazareth no reportan dato. 
Se evidencia que la especialidad médica con mayor demanda es Ginecobstetricia, seguido de Medicina Interna, Cirugía general y Pediatría.

HOSPITALES MEDIANO NIVEL DE COMPLEJIDAD

\begin{tabular}{|l|l|}
\hline NOMBRE DE LA E.S.E. & \multicolumn{1}{c|}{ CAMIS Y/O HOSPITALES } \\
\hline \multirow{3}{*}{ HOSPITAL DE SUBA } & HOSPITAL DE SUBA \\
\cline { 2 - 2 } & CAMI GAITANA \\
\cline { 2 - 2 } & CAMI PRADO VERANIEGO \\
\cline { 2 - 2 } & CAMI SUBA \\
\cline { 2 - 2 } & CENTRO DE SERVICIOS ESPECIALIZADOS SUBA \\
\hline
\end{tabular}

\begin{tabular}{|l|l|}
\hline \multirow{2}{*}{ HOSPITAL ENGATIVÁ } & HOSPITAL ENGATIVÁ \\
\cline { 2 - 2 } & CAMI EMAUS \\
\hline
\end{tabular}

\begin{tabular}{|l|l|}
\hline \multirow{2}{*}{ HOSPITAL FONTIBÓN } & HOSPITAL FONTIBÓN \\
\cline { 2 - 2 } & CAMI FONTIBON \\
\hline
\end{tabular}

\begin{tabular}{|l|l|}
\hline \multirow{3}{*}{ HOSPITAL CENTRO ORIENTE } & HOSPITAL JORGE ELIECER GAITÁN - GUAVIO \\
\cline { 2 - 2 } & CAMI PERSEVERANCIA \\
\cline { 2 - 2 } & CAMI SAMPER MENDOZA \\
\hline
\end{tabular}

\begin{tabular}{|c|c|}
\hline HOSPITAL MEISSEN & HOSPITAL MEISSEN \\
\hline HOSPITAL SAN BLAS & HOSPITAL SAN BLAS \\
\hline HOSPITAL TUNJUELITO & HOSPITAL TUNJUELITO \\
\hline \multirow{3}{*}{ HOSPITAL TUNJUELITO } & CAMI VENECIA \\
\hline & UNIDAD DE MEDICINA INTERNA \\
\hline & UNIDAD MATERNO INFANTIL EL CARMEN \\
\hline
\end{tabular}

De los 8 hospitales que pertenecen a esta categoría, se solicitó la información a 7 (No se incluyó Bosa), de los cuales el 100\% reportó la información.

NÚMERO DE REFERENCIAS SOLICITADAS EN EL SERVICIO DE URGENCIAS EN EL HOSPITAL CUALQUIER TRIAGE VS NÚMERO DE REFERENCIAS EN URGENCIAS VITALES EN LOS AÑOS 2012, 2013 Y DE ENERO A JULIO DE 2014

REFERENCIAS EN URGENCIAS VITALES PARA EL AÑO 2012 


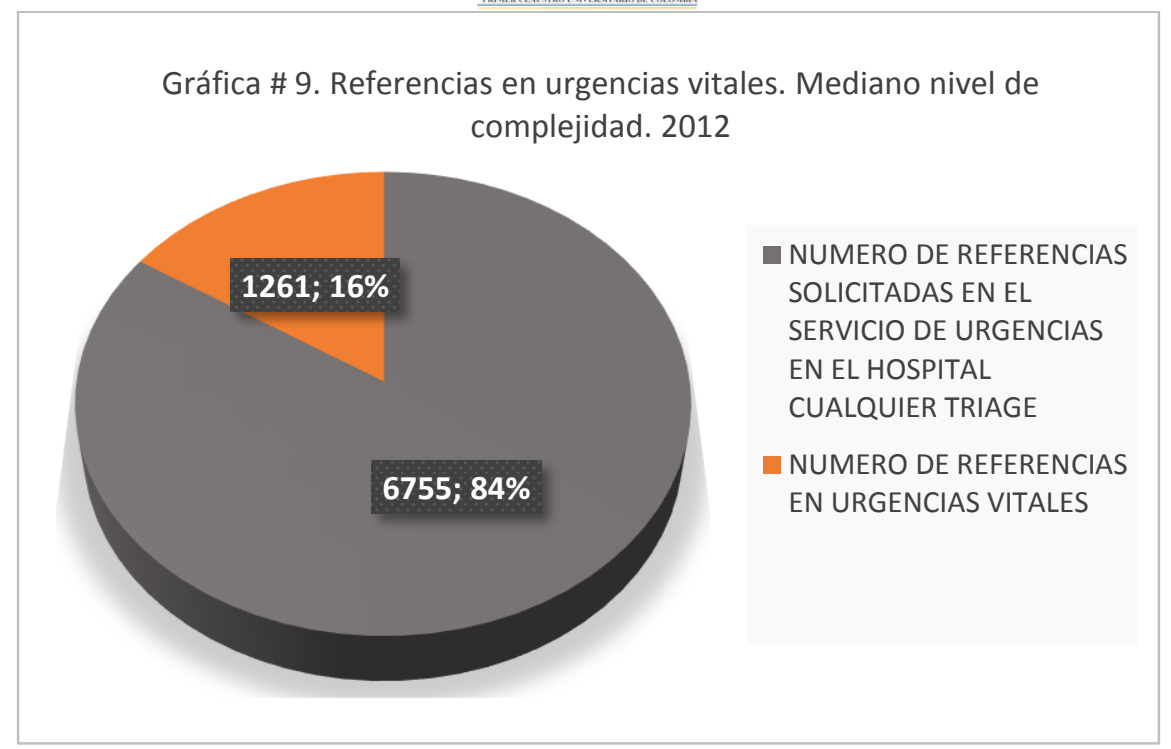

El análisis se realizó para el ítem de referencias en urgencias vitales con una proporción de muestra del 28.5\% (2/7), donde Engativá refiere: "En el Hospital Engativá, se brinda atención médica a TODOS los pacientes que la requieren. Haciendo énfasis en los pacientes con Triage 1, con los medios y recursos técnico científicos con los que se cuenta en la institución; hasta estabilizar el paciente; elemento constitutivo de la atención inicial de urgencias." Meissen no reporta datos para el 2012, Fontibón incluye éste dato en el ítem de Referencias en urgencias, cualquier triage.

Del 100\% (6755) de referencias solicitadas en el servicio de urgencias, el 9\% (1261) corresponden a referencias en urgencia vital. 


\section{REFERENCIAS EN URGENCIAS VITALES PARA EL AÑO 2013}

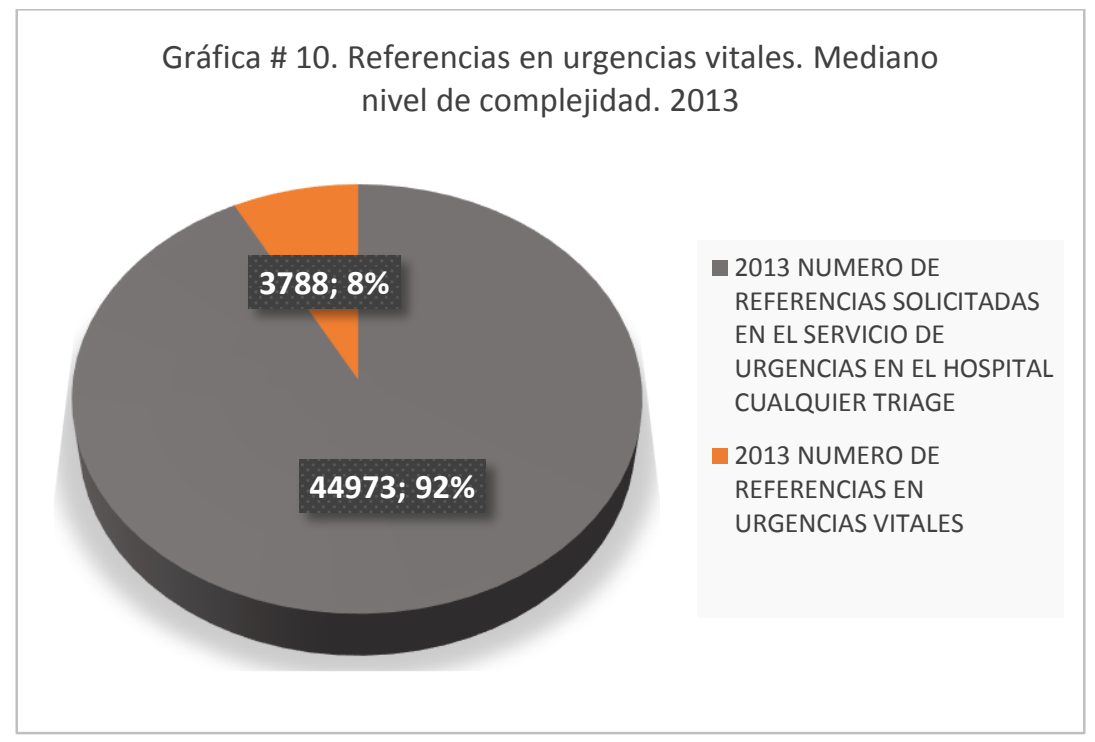

El análisis se realizó para el ítem de referencias en urgencias vitales con una proporción de muestra del $57.1 \%$ (4/7), Engativá menciona nuevamente el texto ya citado, Fontibón incluye el dato en el número de referencias cualquier triage, San Blas no reporta el dato.

Del $100 \%$ (44.973) de referencias solicitadas en el servicio de urgencias, el $8 \%$ (3.788) corresponde a referencias en urgencia vital.

\section{REFERENCIAS EN URGENCIAS VITALES DE ENERO A JULIO DE 2014}

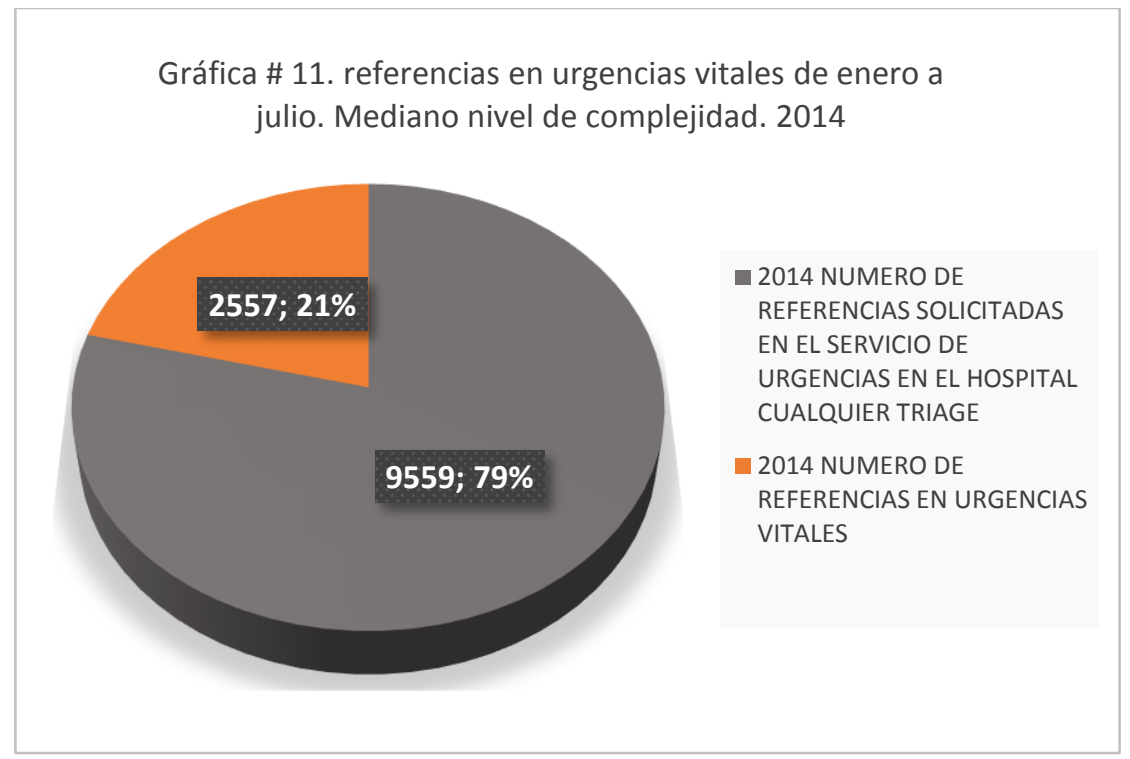


El análisis se realizó para el ítem de referencias en urgencias vitales con una proporción de muestra del $57.1 \%$ (4/7), Engativá menciona nuevamente el texto ya citado, Fontibón incluye el dato en el número de referencias cualquier triage, San Blas no reporta el dato.

Del $100 \%$ (9.559) de referencias solicitadas en el servicio de urgencias, el $21 \%$ (2.557) corresponden a referencias en urgencia vital.

\section{COMPORTAMIENTO EN LA SOLICITUD DE REFERENCIAS VITALES EN LOS AÑOS 2012, 2013 Y DE ENERO A JULIO DE 2014}

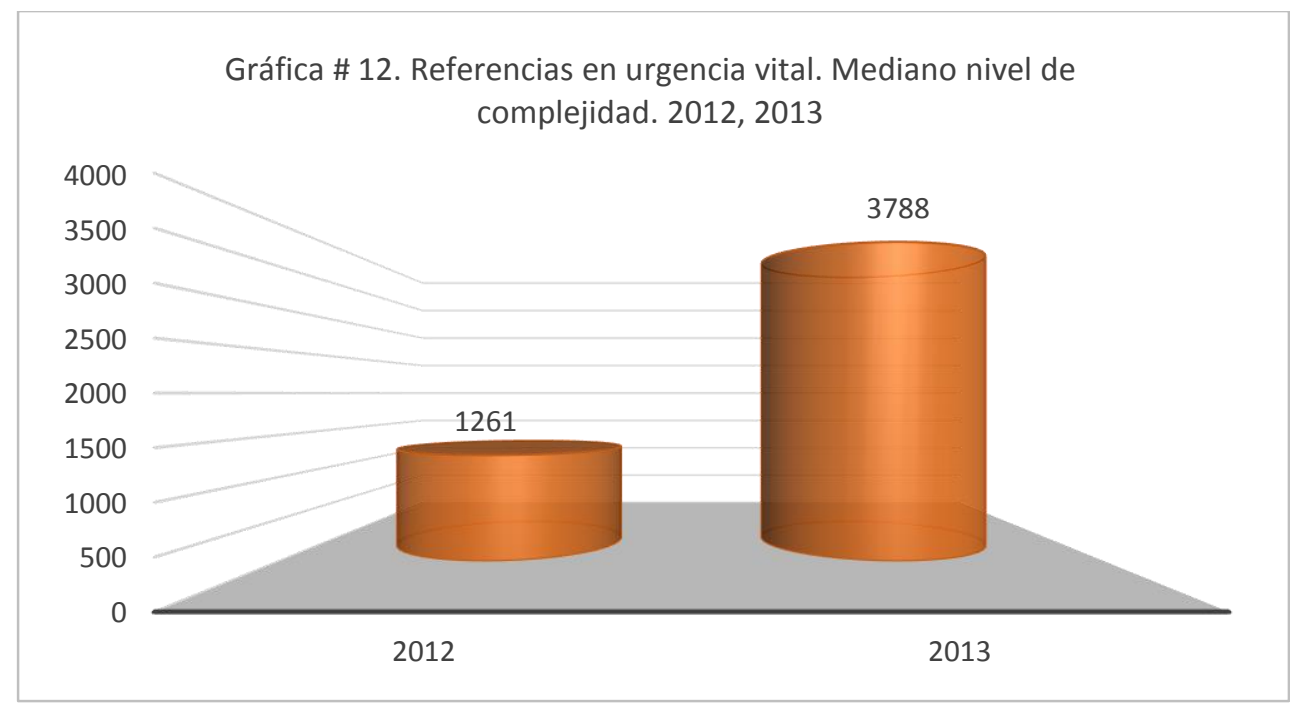

Se evidencia que hubo un ascenso importante en el número de referencias en urgencias vitales, donde el 2012 muestra un número significativamente menor en comparación con los años siguientes, lo que puede deberse a un aumento en el registro y medición del dato, bien sea como control interno o utilización del aplicativo SIRC. 


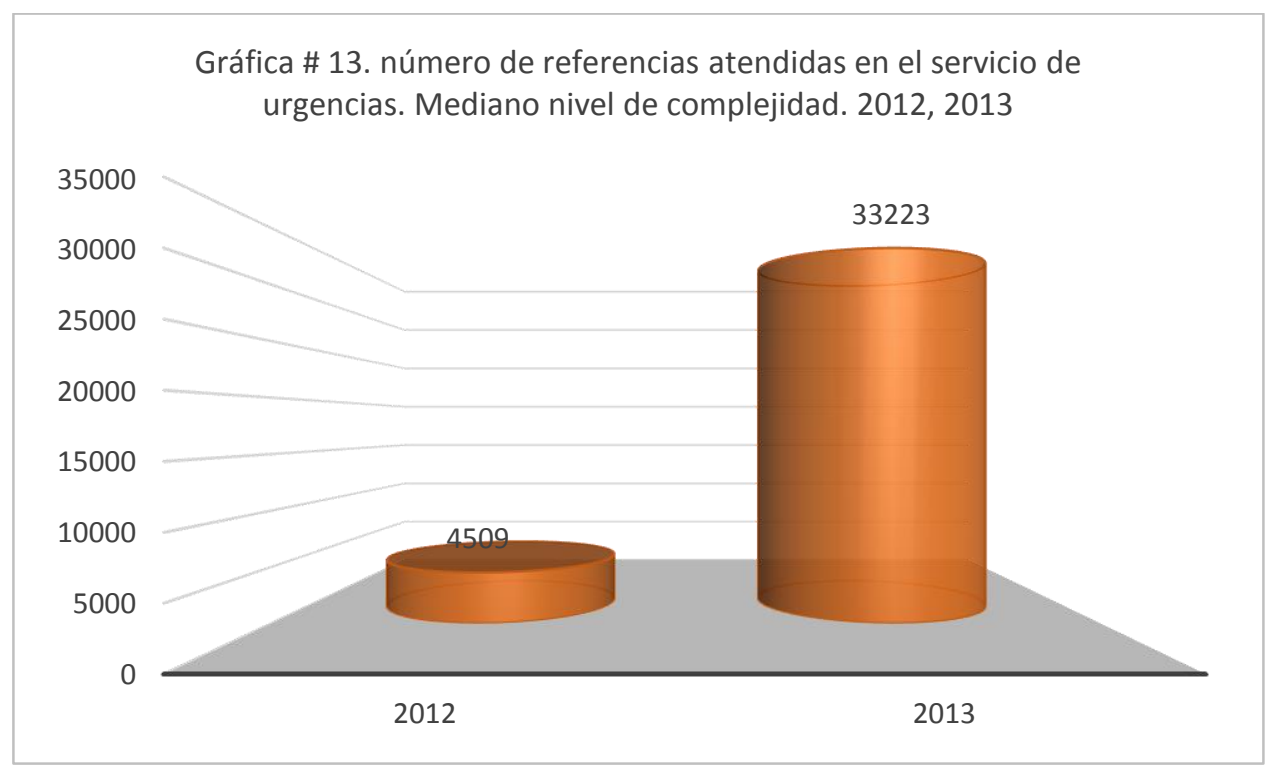

Para el año 2012, tomando como referencia una muestra del 42,8\% (Reporte: 3/7), teniendo en cuenta que el Hospital de Engativá refiere: "Este aspecto se está adelantando con el personal de sistemas, con el fin de poder discriminar la información por turnos diurnos y nocturno. Agradecemos su colaboración en la espera de la entrega de la información. Con el fin de dar información acerca de estos tiempos." El Hospital de Suba y Meissen no reportan el dato. Centro Oriente es el Hospital con el mayor reporte con 28.986 seguido de Tunjuelito con: 3.246, el menor número lo presentó Fontibón con 1234.

Para el 2013, Se evidencia el mayor pico tomando como dato una muestra del 71.4\% (Reporte: 5/7). Centro Oriente continúa siendo el Hospital con el mayor número con 28.738 casos, seguido de Tunjuelito con 3.523 , el menor número lo presentó Fontibón con 772 y Meissen con 184. Suba reporta 1.492 Referencias generadas en urgencias, por lo cual no se toma el dato, teniendo en cuenta que no contesta la solicitud. San Blas reporta 6.4 como promedio.

Para el periodo de enero a julio de 2014, se realiza el análisis tomando como dato una muestra del $71.4 \%$ (Reporte: $5 / 7$ ), el mayor número lo reporta Centro Oriente con 15.480 Referencias atendidas en el servicio de urgencias, seguido de Tunjuelito con: 2.621, los demás hospitales muestran un número inferior, Fontibón reporta 671, Meissen reporta 184, San Blas reporta 6.4 como promedio al igual que para el 2013, Suba describe: referencias generadas: promedio de 608, por lo cual no se tiene en cuenta el dato por no responder la solicitud. 
Para el año 2012, el único Hospital que reportó servicios tercerizados fue Engativá: Radiología, Cardiología, Gastroenterología, Oftalmología, Otorrinolaringología, Ortopedia y Urología, Tunjuelito, Centro Oriente y Fontibón, refieren no contar con servicios tercerizados. Suba, Meissen y San Blas no reportan dato.

Para el año 2013 y el periodo de enero a julio de 2014, San Blas reporta Gastroenterología e Imágenes Diagnósticas tercerizados, los otros hospitales muestran el mismo reporte.

\section{NÚMERO DE PACIENTES QUE FALLECEN SIN RECIBIR LA REFERENCIA SOLICITADA \\ NUMERO DE PACIENTES QUE FALLECEN SIN RECIBIR LA REFERENCIA SOLICITADA 2012}

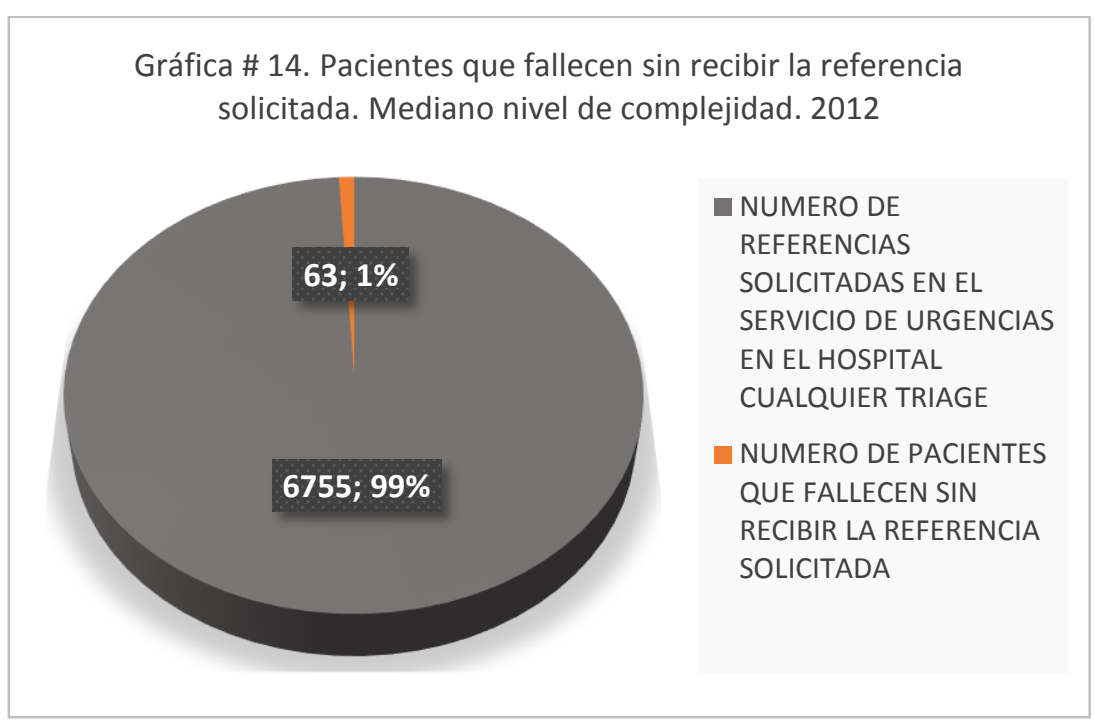

Para el año 2012, del $100 \%$ de referencias solicitadas en el servicio de urgencias (6755), el 1\% (63) murieron en espera de la remisión, los únicos reportes que se recibieron fueron del Hospital de Tunjuelito con 2 personas fallecidas, y Engativá con 61 personas fallecidas. Centro oriente reporta 0, Suba, Meissen, Fontibón y San Blas no reportan dato para este año de medición.

Es fundamental que los hospitales tengan un sistema de información organizado y eficaz que les permita medir y analizar cualquier dato que se requiera, conocer el número de pacientes que mueren en espera de la referencia permite que se evalúe de manera acertada el cumplimiento de la norma en la responsabilidad de las EPS donde: "El diseño, organización, documentación y operación del proceso de 
referencia es obligación de las entidades responsables del pago de servicios de salud, quienes deberán disponer de una red de prestadores de servicios de salud que garanticen la disponibilidad y suficiencia de los servicios en todos los niveles de complejidad a su cargo, así como la disponibilidad de la red de transporte $y$ comunicaciones." (20)

\section{NÚMERO DE PACIENTES QUE FALLECEN SIN RECIBIR LA REFERENCIA SOLICITADA 2013}

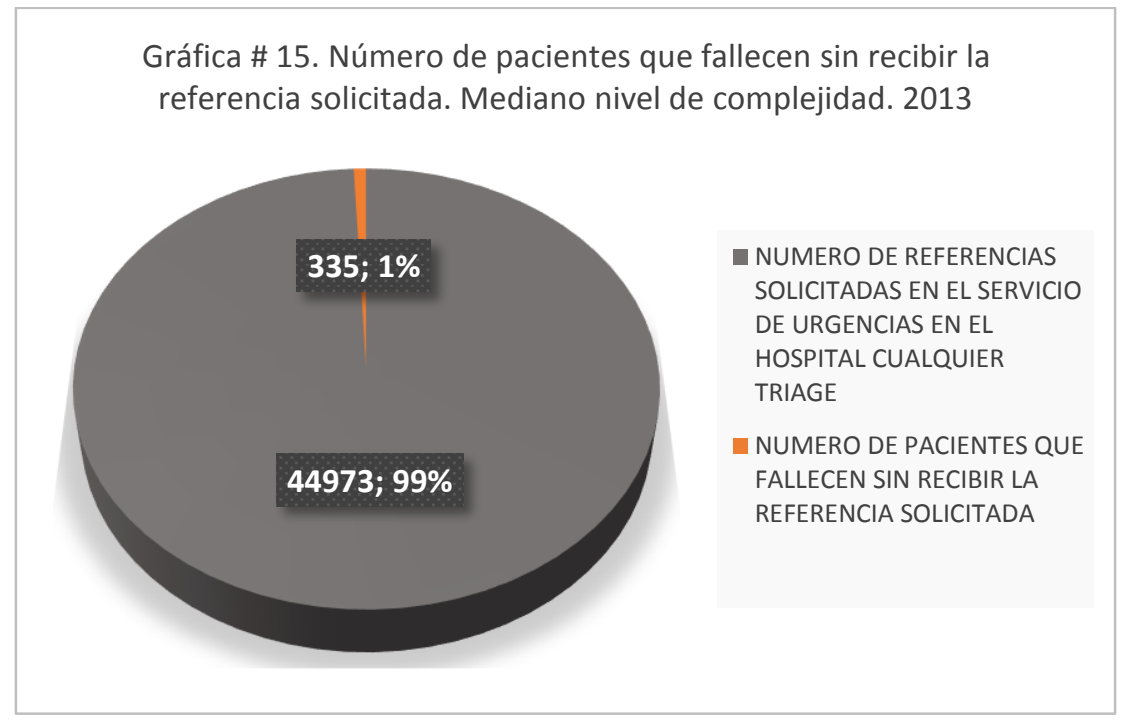

Para el año 2013, el reporte aumentó de manera importante. Del 100\% (44.973) de referencias solicitadas en el servicio de urgencias, el 1\% (335) murieron en espera de la remisión. Se evidencia que el mayor reporte lo realiza Meissen con 104 casos, seguido de Fontibón con 77, Engativá con 75 y Suba con 73. Los hospitales con menor reporte son San Blas y Tunjuelito con 3 casos cada uno, Centro Oriente nuevamente reporta 0 casos. 

SOLICITADA DE ENERO A JULIO DE 2014

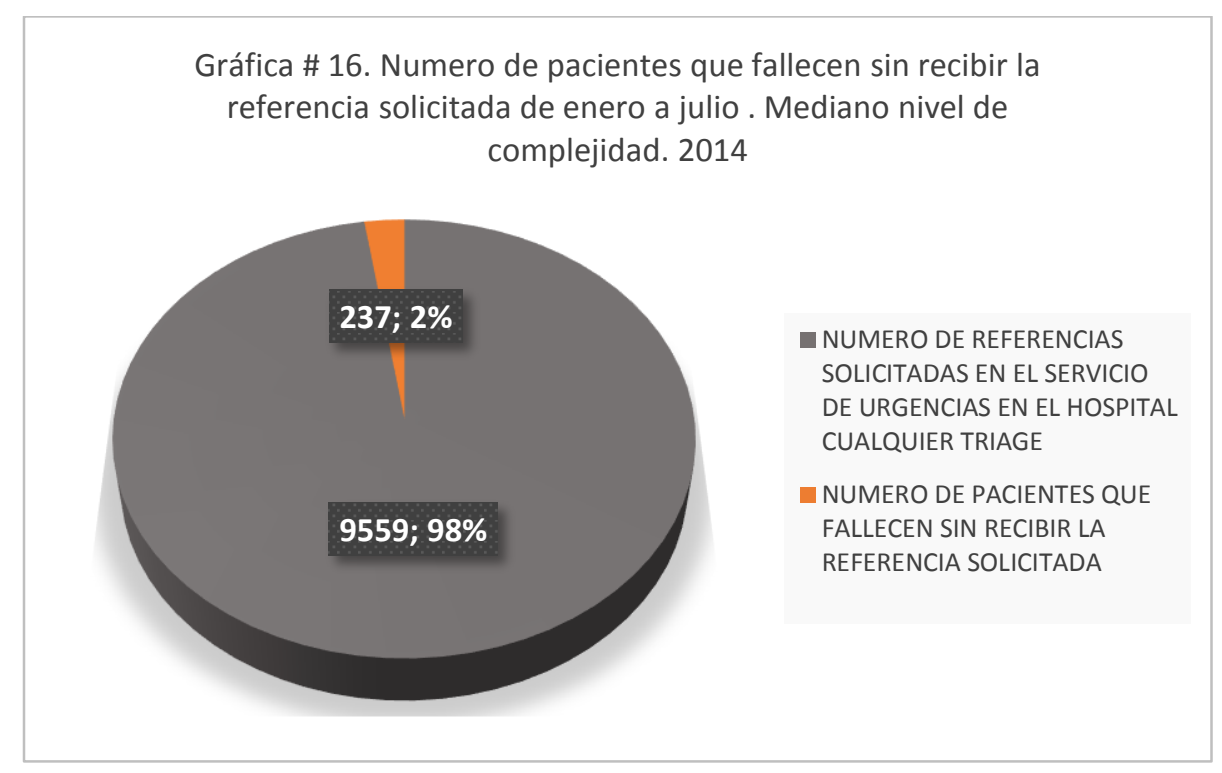

Para el periodo de enero a julio de 2014 , del $100 \%$ (9.559) de referencias solicitadas, el $2 \%$ (237) de pacientes fallecieron en espera de la referencia.

Meissen es el hospital que presenta el mayor reporte con 75 casos, seguido de Fontibón con 66 casos y Engativá con 63, Suba reporta 33 casos. Tunjuelito, San Blas y Centro Oriente reportan 0 . Vale la pena revisar que Centro Oriente durante los tiempos de medición siempre reportó 0 . 


\section{COMPORTAMIENTO EN EL NÚMERO DE PACIENTES QUE FALLECEN SIN RECIBIR LA REFERENCIA SOLICITADA 2012, 2013 Y DE ENERO A JULIO DE 2014}

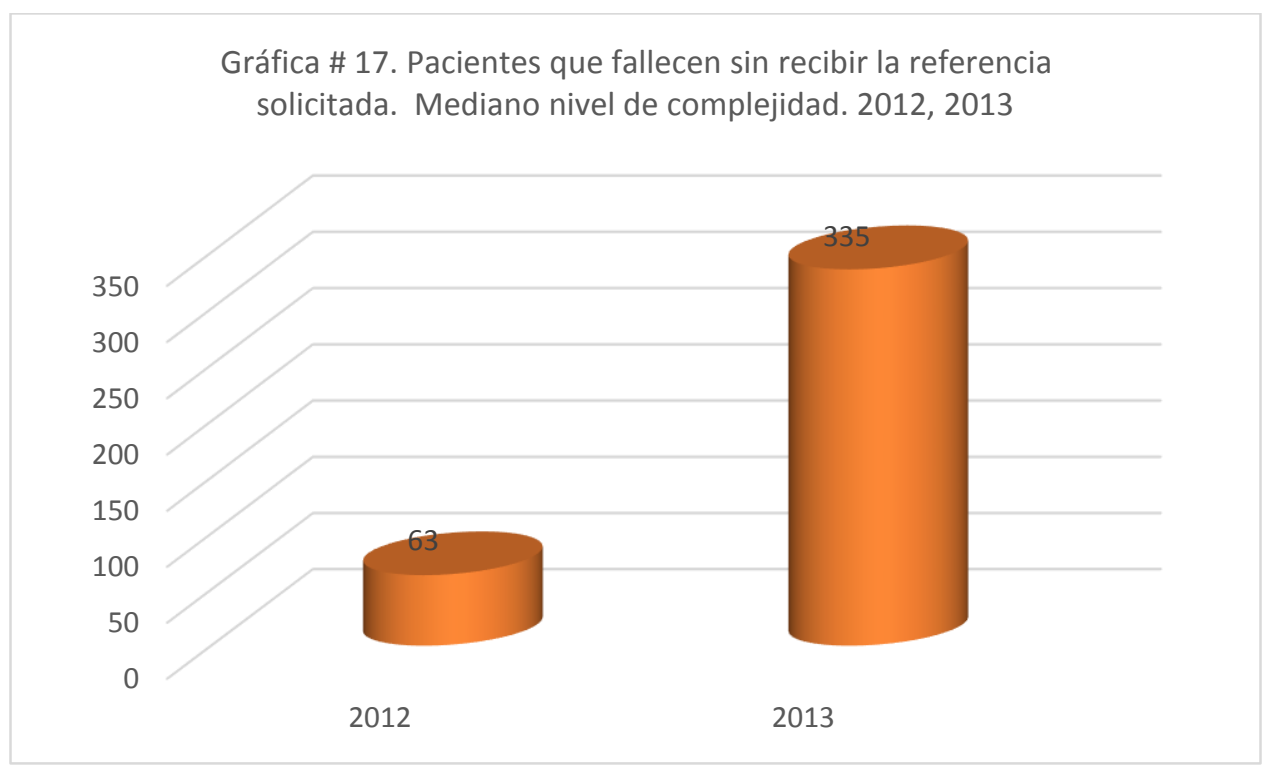

El 2012 se caracterizó por presentar el menor número de casos. Pueden citarse hipótesis como subregistro o un sistema de información poco confiable que no le permite a los hospitales realizar un reporte real, es importante tener en cuenta que el análisis se realiza con el $42.8 \%$ (3/7) de los datos ya que 4 hospitales no reportaron el dato. En el 2013 se evidencia el mayor pico, donde el 100\% de la muestra reportó el dato. Para el periodo de enero a julio de 2014, se evidencia un número importante teniendo en cuenta que el $42.8 \%$ reportan el dato en 0 . Sin embargo, es importante continuar insistiendo en la importancia del reporte, teniendo en cuenta que éste se convierte en una herramienta fundamental que permitirá evidenciar el comportamiento de oportunidad y continuidad que están obligados a garantizar las EPS. 


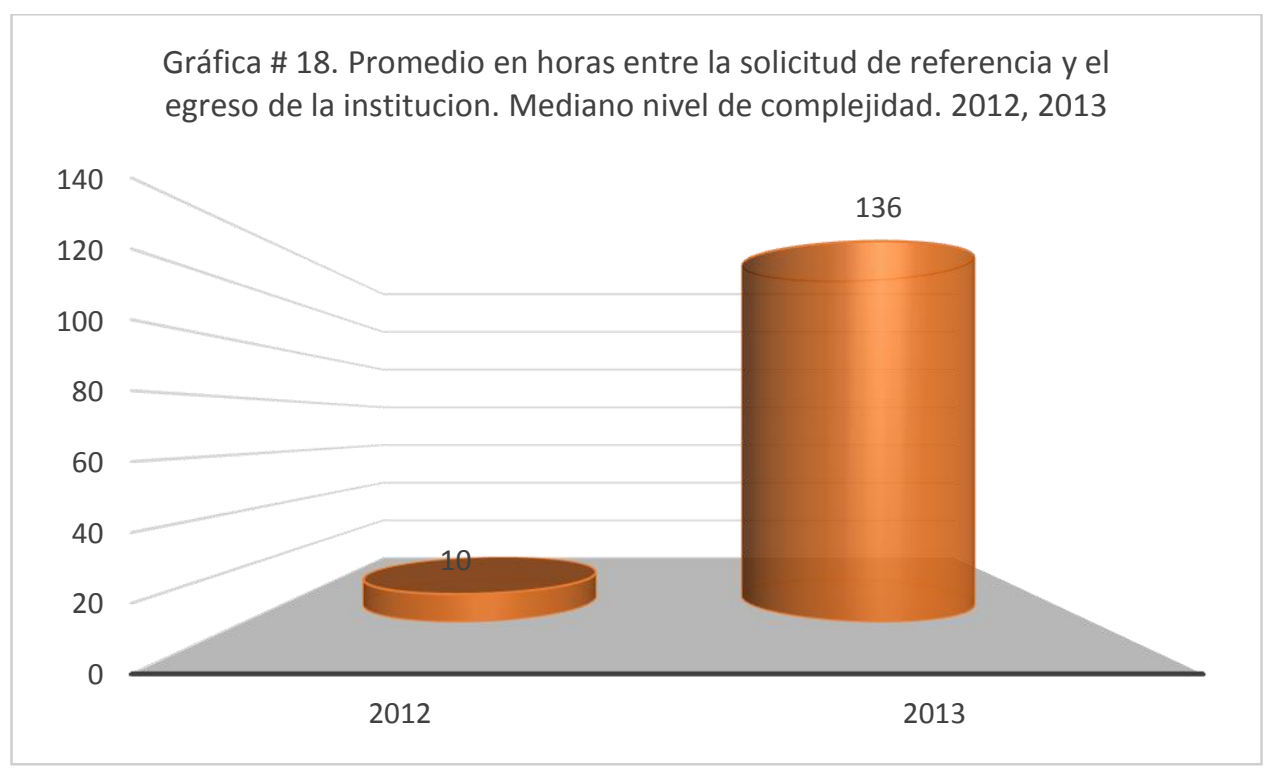

En el 2012, solo el 42.8\% (3/7) reportaron el dato. Se evidencia que para este año el promedio estuvo en 10 horas, pero se debe tener en cuenta que 4 hospitales no realizaron el reporte. El Hospital con el mayor promedio en horas de espera fue Fontibón con 30 horas (1.25 días), seguido de Tunjuelito con 12 horas y Centro Oriente con 8 Horas. Engativá refiere que no es medible, Suba, Meissen y San Blas no reportan dato.

Para el año 2013, se realiza el análisis con el 85.7\% (6/7) de la muestra, excluyendo a Suba ya que entrega un dato que no es claro. El promedio para este año fue de 136 horas, (5.6 días). El hospital con el mayor promedio en horas de espera fue Meissen con un total de 494 horas (20.5 días), seguido de San Blas con 48 horas (2 días), Engativá con 38.4 (1.6 días), Tunjuelito con 22 horas, Fontibón con 18 horas y Centro Oriente con 12 horas, Suba no se tuvo en cuenta debido a que reporta un dato que no es claro para su medición.

Para el periodo de enero a julio de 2014, se realiza el análisis con el $85.7 \%(6 / 7)$ de la muestra, excluyendo a Suba ya que entrega un dato que no es claro. Se evidencia el mayor pico con 143 horas, (6 días), donde Meissen es el hospital con el mayor promedio de horas de espera con 384 horas (16 días) seguido de San Blas con 55.2 (2.3 días), Fontibón con 43 horas (1.7 días), Tunjuelito con 34 horas (1.4 días), Engativá con 28.8 horas (1.2 días ) y Centro Oriente con 12 horas. 
Es fundamental que se pongan en marcha estrategias adecuadas, oportunas y eficaces que permitan mejorar los tiempos bajo el lineamiento establecido por la norma, donde se minimice el tiempo de espera y con ello el riesgo de morbimortalidad.

\section{HOSPITALES ALTO NIVEL DE COMPLEJIDAD}

\section{HOSPITALES QUE SE ANALIZAN}

- H. EL TUNAL

- H. LA VICTORIA

- H. OCCIDENTE DE KENNEDY

- H. SANTA CLARA

- H. SIMON BOLIVAR

De los 5 Hospitales de alto nivel de complejidad con los que cuenta el Distrito, se hizo la solicitud a los 5 de los cuales el 100\% reportó la información.

\section{ANÁLISIS DE LA INFORMACIÓN}

NÚMERO DE REFERENCIAS SOLICITADAS EN EL SERVICIO DE URGENCIAS EN EL HOSPITAL CUALQUIER TRIAGE VS NÚMERO DE REFERENCIAS EN URGENCIAS VITALES

\section{REFERENCIAS EN URGENCIAS VITALES PARA EL AÑO 2012}

Gráfica \# 19. Referencias en urgencias vitales. Alto nivel de complejidad. 2012

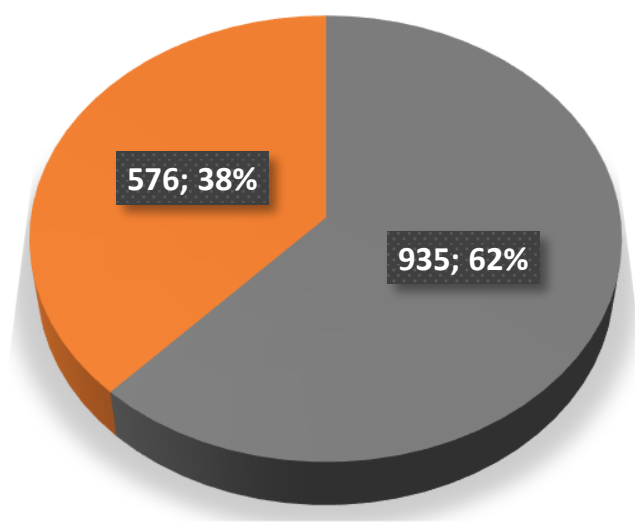

- NUMERO DE REFERENCIAS SOLICITADAS EN EL SERVICIO DE URGENCIAS EN EL HOSPITAL CUALQUIER TRIAGE

- NUMERO DE REFERENCIAS EN URGENCIAS VITALES 
El análisis se realiza con el $60 \%$ de la información para ambos datos. Para el año 2012 en promedio, del 100\% de las referencias solicitadas en urgencias en los hospitales de alta complejidad el 38\% correspondió a urgencias vitales. Como dato de interés, el Hospital Tunal y Santa Clara no reportan dato de referencias solicitadas cualquier Triage, el Hospital Santa Clara reporta 0 para urgencias vitales, el hospital de Kennedy específica para urgencias vitales que no aplica, el Hospital Simón Bolívar reporta el mismo dato para los 2 ítems bajo el argumento: "En el sistema de información en el que se reporta dicha información no se discrimina las urgencias y paciente hospitalizado. Por otra parte, las referencias no dependen de la llamada urgencia vital, dado que esta debe ser atendida inmediatamente con los recursos institucionales." Por lo que solo se utiliza el dato para evidenciar el número de urgencias solicitadas cualquier triage.

Con base a la información suministrada, se evidencia que los datos entregados son una muestra promediada, pero se hace fundamental conocer la demanda de urgencias vitales que manejan estas instituciones, teniendo en cuenta que para el Distrito, 5 hospitales de alto nivel de complejidad son un número bajo para la gran cantidad de pacientes que pertenecen al régimen subsidiado y son quienes reciben la mayor afluencia de referencias de acuerdo a la complejidad del servicio. Se debe revisar el concepto de no aplica, teniendo en cuenta que las instituciones, independientemente de su complejidad, no siempre tendrán disponibilidad y servicios ofertados.

\section{REFERENCIAS EN URGENCIAS VITALES PARA EL AÑO 2013}

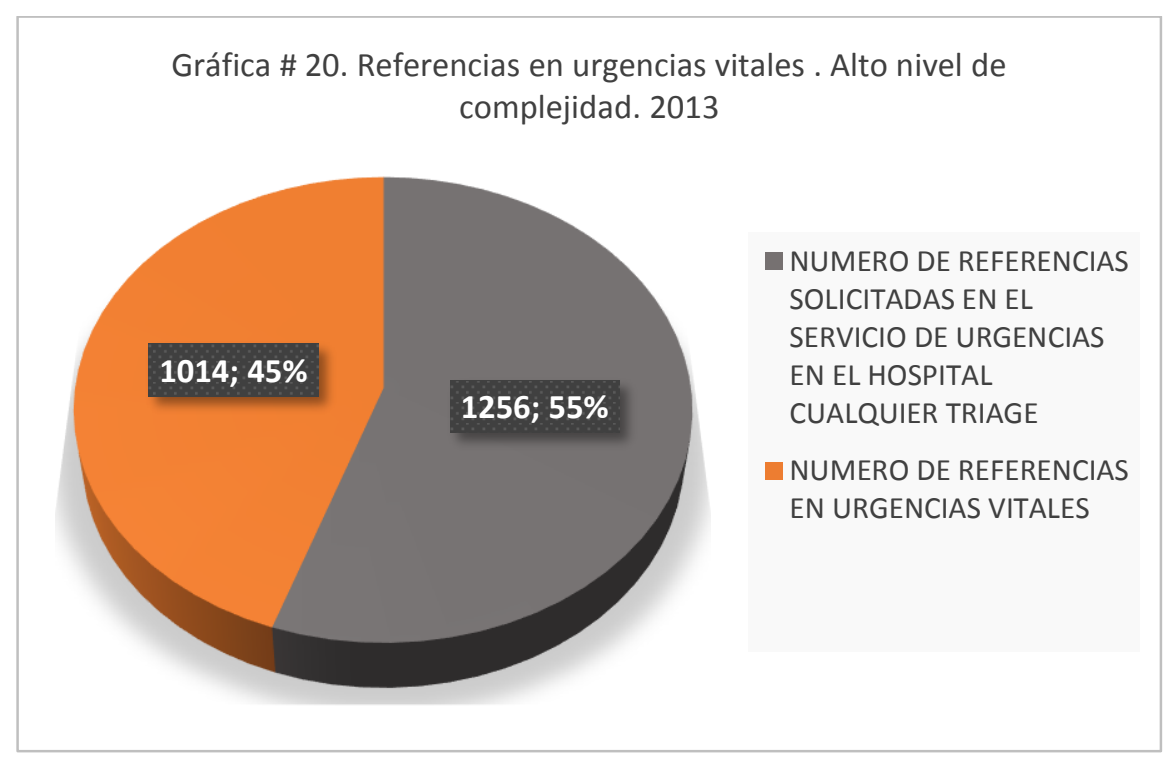


El análisis se realiza con el $60 \%$ de la información para ambos datos. Para el año 2013 , en promedio, del $100 \%$ de las referencias solicitadas en urgencias en los hospitales de alto nivel de complejidad el $45 \%$ correspondió a urgencias vitales.

Es importante destacar que el Hospital Santa Clara no reporta referencias de cualquier triage y reporta 0 para referencias en urgencias vitales, el Hospital Simón Bolívar totaliza el dato, con base al argumento anteriormente especificado, Tunal no reporta dato de referencias para cualquier triage, y el hospital de Kennedy refiere que no aplica para el dato de referencias en urgencias vitales. Por lo anterior, se obtiene un dato estimado sujeto a sesgo de información, teniendo en cuenta que para el análisis de referencias solicitadas para cualquier triage se realiza con el $60 \%$ (3/5) de los datos, para el segundo ítem que especifica el número de urgencias vitales, se hace el análisis con el mismo porcentaje.

\section{REFERENCIAS EN URGENCIAS VITALES DE ENERO A JULIO DE 2014}

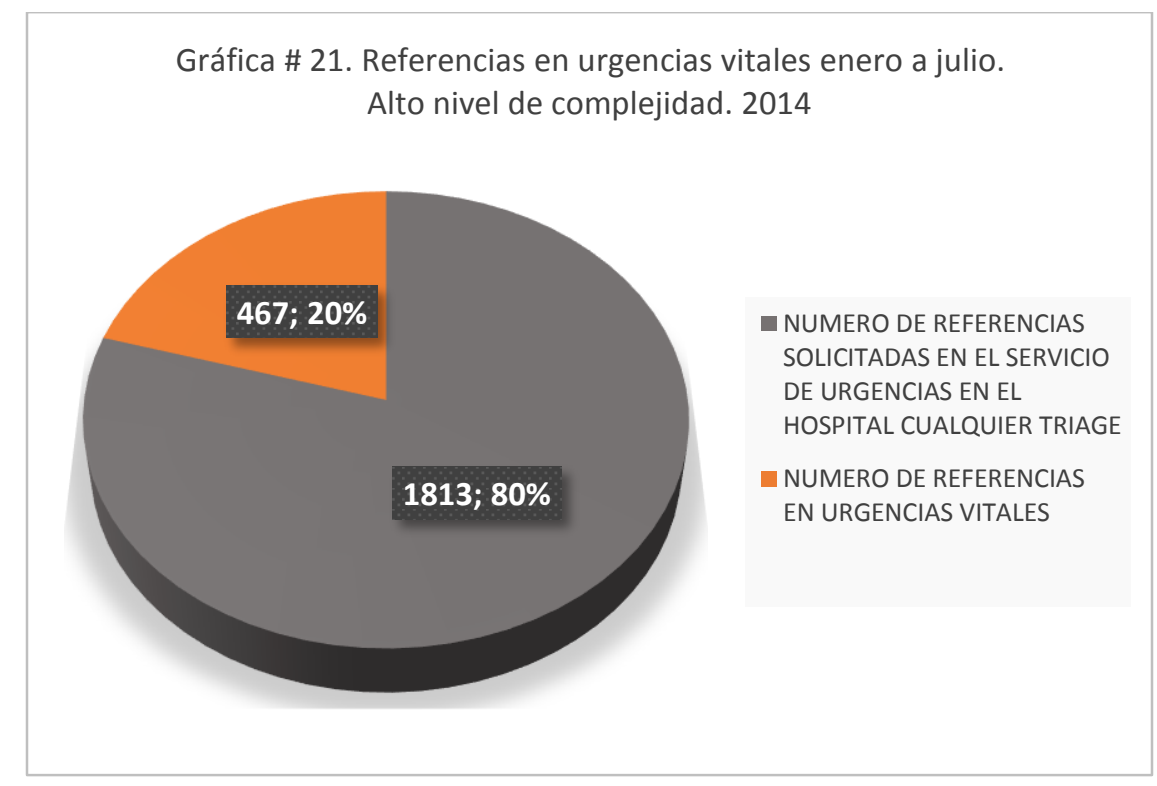

El análisis se realiza con el $60 \%$ de la información para ambos datos. Para el periodo de enero a julio de 2014 en promedio, del 100\% de las referencias solicitadas en urgencias en los hospitales de alto nivel de complejidad el $20 \%$ correspondió a urgencias vitales.

Es importante destacar que el Hospital Santa Clara no reporta referencias de cualquier triage y reporta 0 para referencias en urgencias vitales, el Hospital Simón Bolívar totaliza el dato, con base al argumento anteriormente especificado, El Tunal no reporta dato de referencias para cualquier triage, y el hospital de Kennedy refiere que no aplica para el dato de referencias en urgencias vitales. 
Como se explicó anteriormente, es indispensable que las instituciones registren estos datos, lo cual permitirá evidenciar la oferta y demanda tanto en el servicio de urgencias como en urgencias vitales, las cuales se constituyen en un factor importante para el análisis en la suficiencia de la red, al mismo tiempo para evidenciar en dato real el comportamiento de este servicio, en el cual se ponen en juego varios factores que determinarán la sobrevida del paciente, teniendo en cuenta que en el Distrito contamos con 5 hospitales de alto nivel de complejidad y en el cual se hace evidente que la demanda supera la oferta de la capacidad instalada.

\section{COMPORTAMIENTO EN LA SOLICITUD DE REFERENCIAS EN URGENCIAS VITALES EN LOS AÑOS 2012, 2013 Y DE ENERO A JULIO DE 2014}

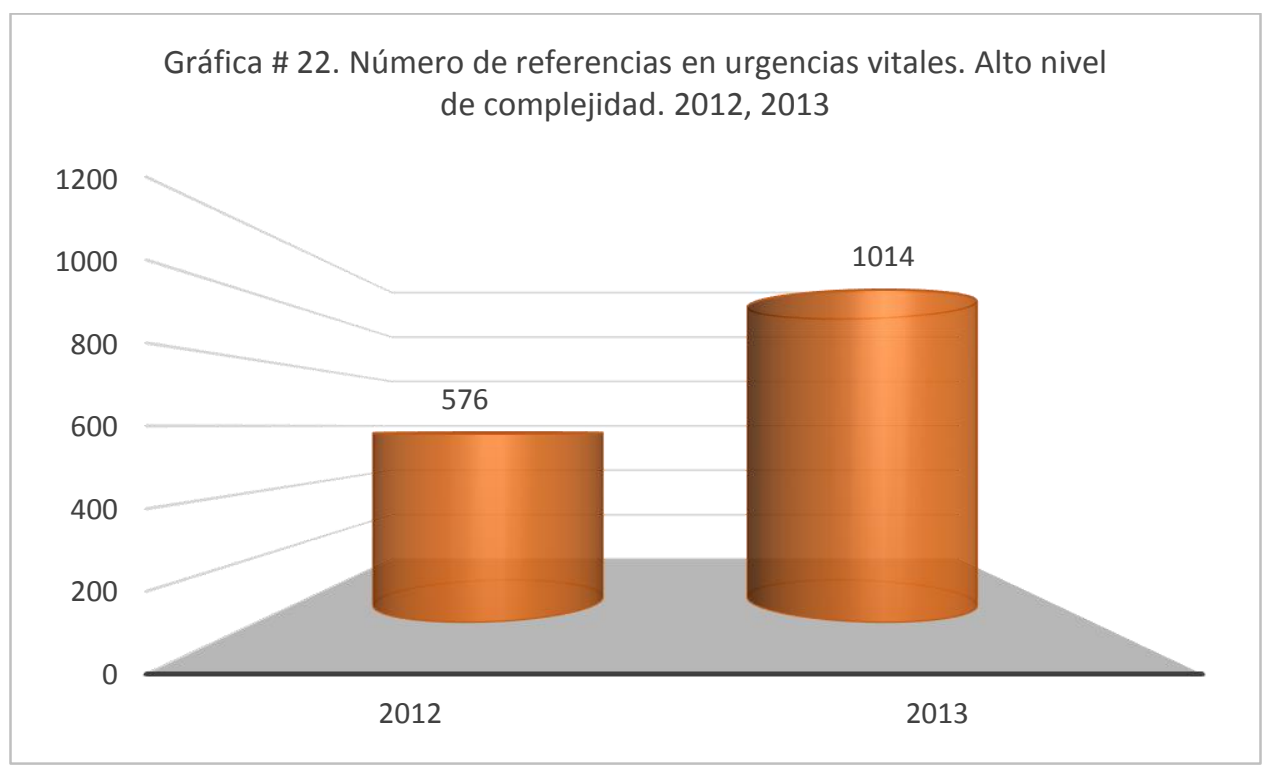

El Hospital Simón Bolívar no discrimina el tipo de Referencia, por lo cual el dato reportado (el mismo para referencias cualquier triage y referencias en urgencias vitales) no se tuvo en cuenta para medir referencias en urgencias vitales. Kennedy en los periodos de análisis reporta no aplica y el Hospital Santa Clara nunca remitió un paciente en urgencia vital, el reporte más representativo durante todo el periodo fue realizado por el Hospital el Tunal, el Hospital la Victoria reportó el mismo dato tanto para el 2012 como para el 2013.

De acuerdo a la información obtenida ( $60 \%$ de la muestra), se evidencia que el año 2013 se caracterizó por tener un incremento en el número de referencias de urgencias vitales y que el periodo de Enero a Julio de 2014 se acerca de manera importante al dato registrado para el año 2012 si se tiene en cuenta que para el año 
2014 el periodo de análisis es de 7 meses, lo cual indicaría mayor registro o aumento en la demanda de este evento.

\section{NÚMERO DE REFERENCIAS ATENDIDAS EN EL SERVICIO DE URGENCIAS EN LOS TURNOS}

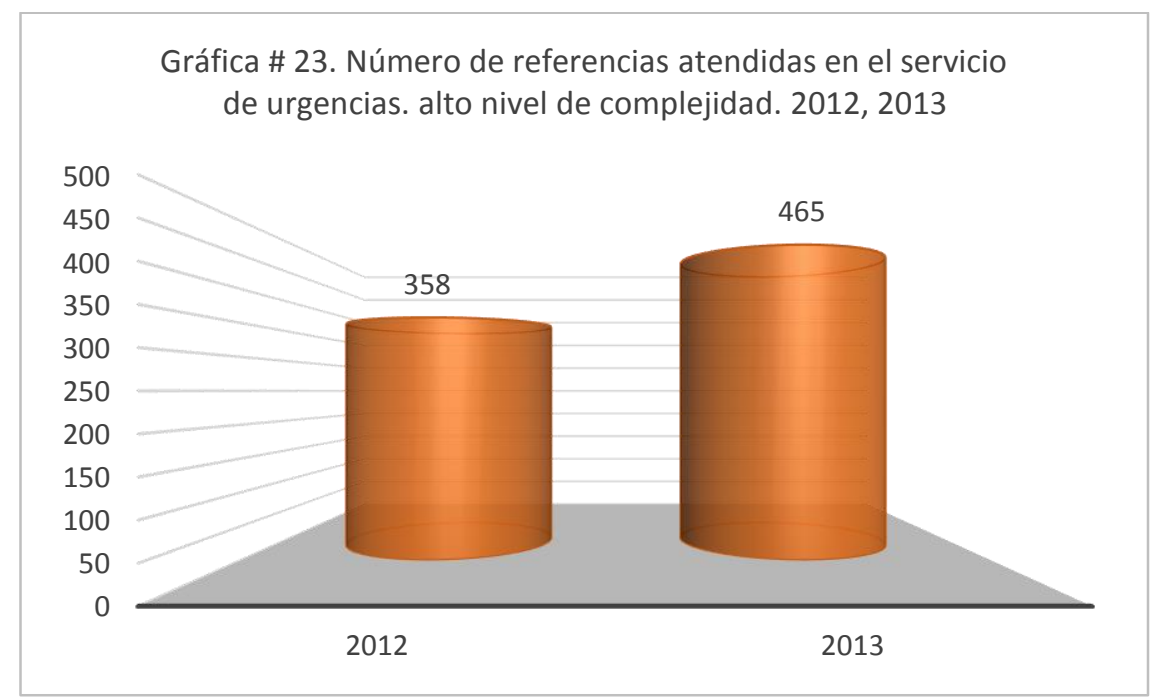

Para este dato, se evidencia que el reporte lo realizaron el Hospital Simón Bolívar y la Victoria. Con base a lo anterior, se obtiene el 40\% (2/5) del reporte, el hospital de Kennedy refiere: "Solo se suministra el número de referencias que ingresan por el servicio de urgencias y cuyo trámite se realizó a través de la oficina de radio de nuestra institución, ya que una gran mayoría de remisiones vienen sin realizar ningún trámite por la oficina de referencia de nuestra institución ya que son direccionadas directamente por las instituciones de salud, la dirección Centro Regulador de Urgencias y Emergencias de la Secretaria Distrital de Salud o los diferentes entes territoriales. "Para el caso de Tunal y Santa Clara, éstos no reportan dato para todo el periodo de análisis.

De acuerdo a los datos obtenidos, se evidencia que hay aumento en el número de referencias atendidas en el turno, lo que reflejaría mayor reporte o aumento de la demanda de servicios de mayor nivel de complejidad, lo que muestra que se hace necesario garantizar la suficiencia de la red que permitan garantizar la oportunidad en la oferta de los servicios requeridos.

\section{NÚMERO DE SERVICIOS TERCERIZADOS CONTRATADOS POR ESPECIALIDAD EN LA INSTITUCION}

De acuerdo a los datos reportados, el Hospital de Kennedy no suministra un dato claro y el Tunal no reporta dato. Los hospitales con el mayor número de servicios tercerizados son: La Victoria con 5, seguido de Simón Bolívar con 3 y Santa Clara con 2. Los servicios que más se tercerizan son: Imágenes diagnósticas, Cardiología y Gastroenterología. Otros servicios tercerizados son: Oftalmología y Nefrología. 
UNIVREIDAD ANAOTOMAS

También se evidencia que en el periodo analizado se tercerizaron en totalidad 10 servicios, dato que se mantuvo refractario durante este periodo.

NÚMERO DE PACIENTES QUE FALLECEN SIN RECIBIR LA REFERENCIA SOLICITADA

NÚMERO DE PACIENTES QUE FALLECEN SIN RECIBIR LA REFERENCIA SOLICITADA 2012

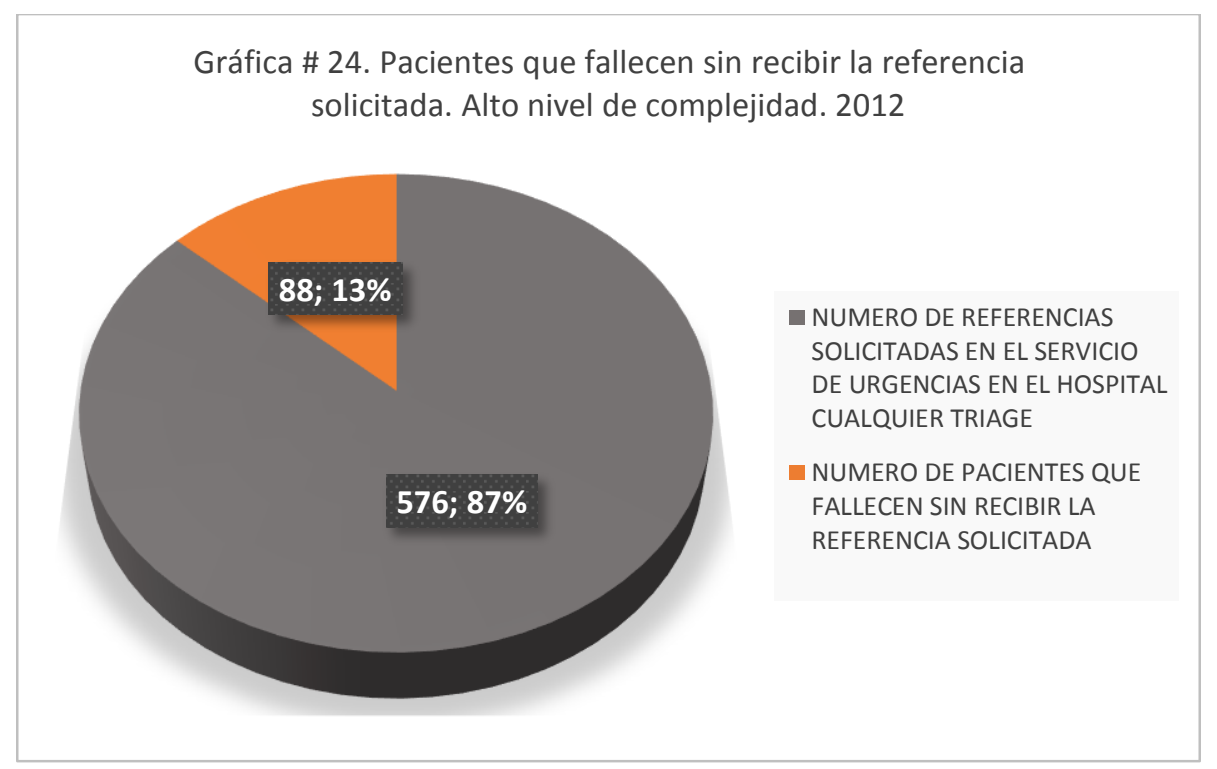

En el año 2012, del 100\% (576) de las referencias solicitadas como urgencia vital el 13\% (88) fallecieron en espera de la remisión.

\section{PACIENTES QUE FALLECEN SIN RECIBIR LA REFERENCIA SOLICITADA 2013}

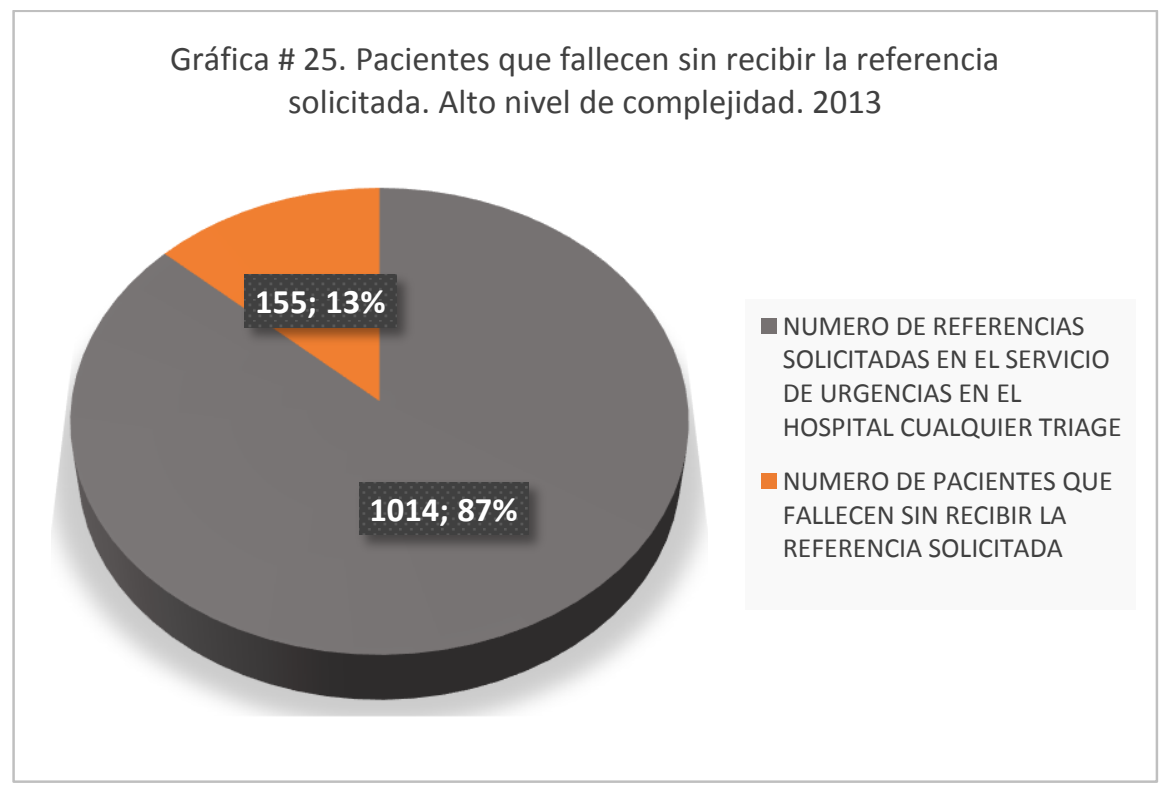


En el año 2013, del 100\% (1.014) de las referencias solicitadas como urgencia vital el 13\% (155) fallecieron en espera de la remisión.

\section{PACIENTES QUE FALLECEN SIN RECIBIR LA REFERENCIA SOLICITADA DE ENERO A JULIO DE 2014}

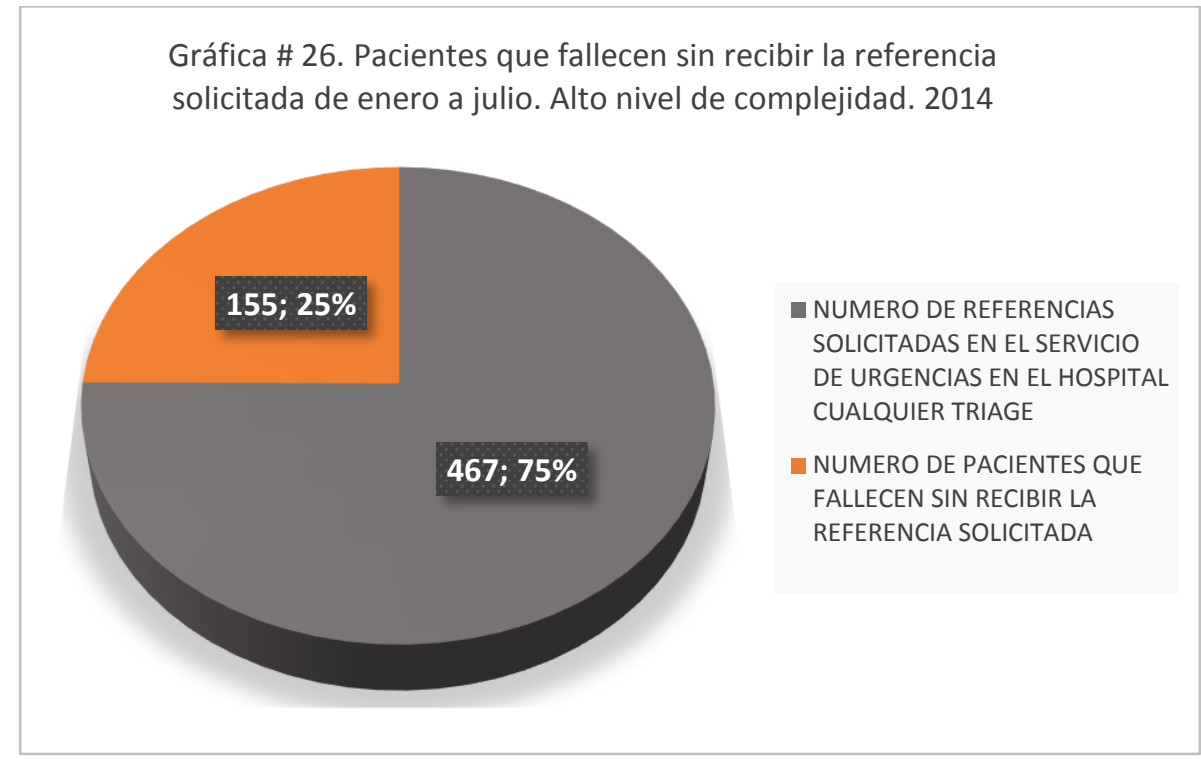

Del 100\% (467) de las referencias solicitadas en el año 2014 como urgencia vital el $25 \%$ (155) fallecieron en espera de la remisión. Como dato de interés, el Hospital la Victoria informa que en su mayoría eran de la EPS Caprecom.

\section{COMPORTAMIENTO DE PACIENTES QUE FALLECEN SIN RECIBIR LA REFERENCIA SOLICITADA EN LOS AÑOS 2012, 2013 Y DE ENERO A JULIO DE 2014}

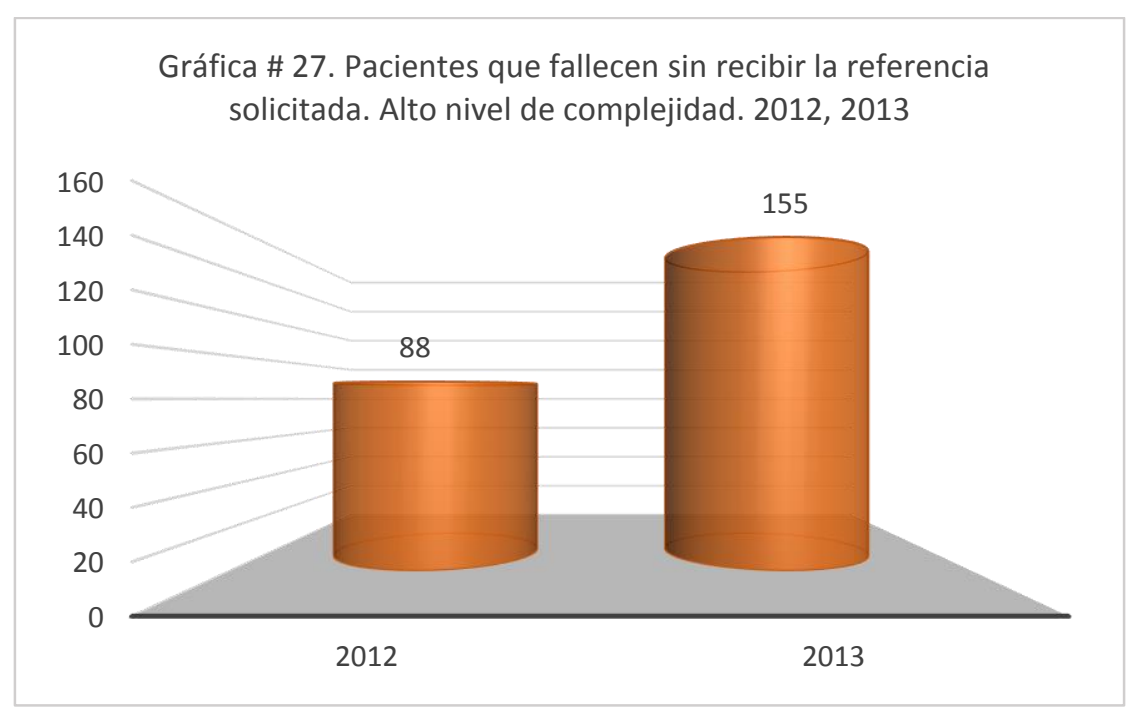


Para el año 2012, el Hospital con el mayor reporte de pacientes fallecidos en espera de la referencia fueron Simón Bolívar con 57, seguido de Kennedy con 20 y en menor proporción la Victoria con 7 y Santa Clara con 4, el Tunal reporta 0 para este dato, información que valdría la pena analizar, teniendo en cuenta que son los hospitales con la mayor afluencia de pacientes y en el cual la complejidad de los mismos es mayor, por lo anterior se debe revisar si hubo subregistro o el hospital cuenta con una capacidad resolutiva tan amplia en el cual los pacientes no fallecen en la institución en espera de la referencia.

Para el año 2013, el hospital que presentó el mayor reporte fue Kennedy con 48 pacientes, seguido de Santa Clara con 47, Simón Bolívar con 33, Hospital la Victoria con 17, y el Tunal con 10, para este año se evidencia un registro mayor, el Tunal continuó siendo el hospital con el menor número de reportes.

Los años 2013 y el periodo de enero a julio de 2014 presentaron el mismo número de pacientes fallecidos.

Para el periodo de enero a julio de 2014 el hospital con el mayor número de pacientes fallecidos fue Kennedy con 81 casos, seguido de Santa Clara con 34, Simón Bolívar con 23, Tunal con 17 y la Victoria con 13, La Victoria muestra la particularidad que la mayoría de pacientes que fallecen pertenecen a la EPS Caprecom.

Vale la pena mencionar que las instituciones deben tener un registro eficaz, real, oportuno, confiable y actualizado, entre otros, el número de pacientes que fallecen en la espera de referencia, lo cual permitiría evidenciar realizar una gestión adecuada, teniendo en cuenta que con base al Artículo 17 del Decreto 4747 de 2007: "El diseño, organización, documentación y operación del proceso de referencia es obligación de las entidades responsables del pago de servicios de salud, quienes deberán disponer de una red de prestadores de servicios de salud que garanticen la disponibilidad y suficiencia de los servicios en todos los niveles de complejidad a su cargo, así como la disponibilidad de la red de transporte y comunicaciones." (20) 
COMPORTAMIENTO DEL PROMEDIO EN HORAS ENTRE LA SOLICITUD DE REFERENCIA Y EL EGRESO DE LA INSTITUCION

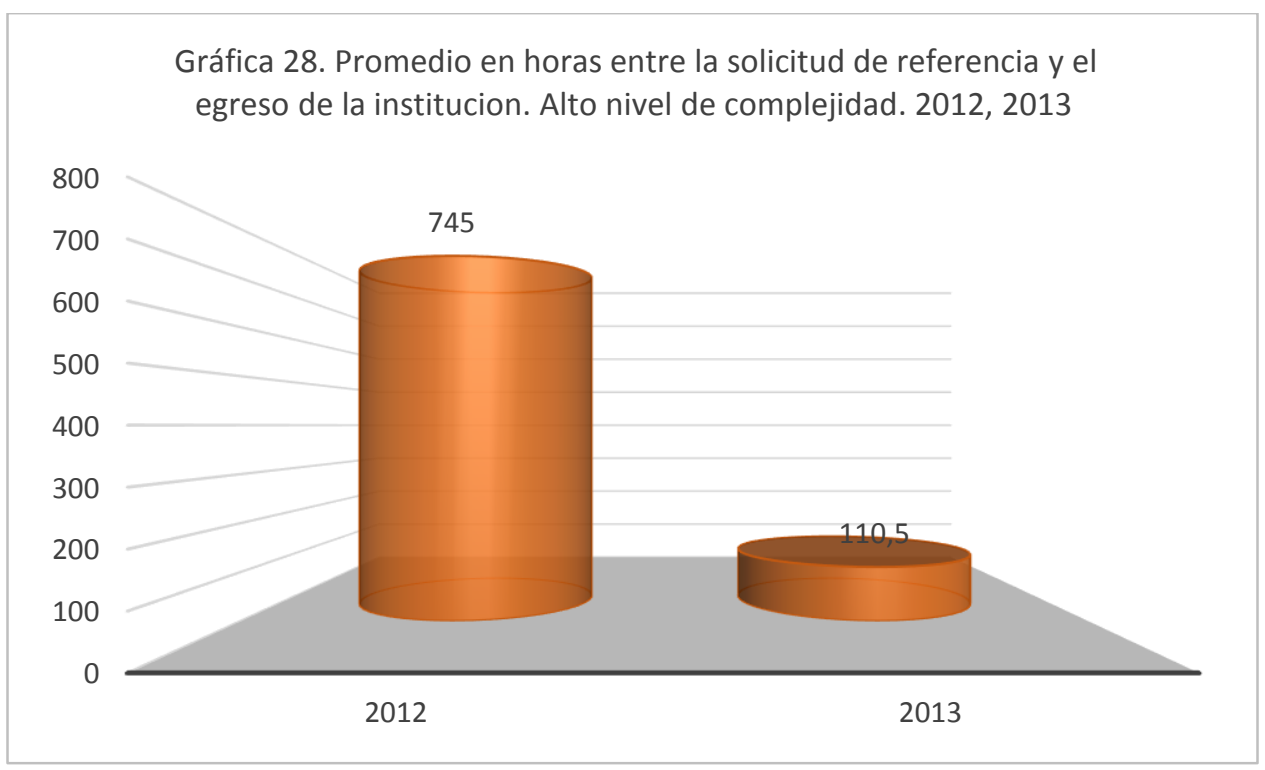

De acuerdo al reporte entregado por los hospitales de alto nivel de complejidad, se evidencia que el 2012 fue el año que presentó mayor promedio en horas: 745 entre la solicitud de la referencia y la realización efectiva de la misma, el 2013 tuvo un descenso significativo con un promedio en horas de 110.5 y el periodo de Enero a Julio de 2014 con un promedio de 56 horas. En términos de días, el 2012 mostró un promedio de 31 días, donde el Tunal fue el hospital con el mayor promedio de horas con un total de 2.136 horas (89 días), seguido de Kennedy con 60 Horas, (2.5 días) Simón Bolívar con 38 y la Victoria con 8,5 horas (Menos de 1 día), valdría la pena revisar cómo se tomó el promedio en horas del Hospital el Tunal, el Hospital Santa Clara no reportó dato.

Para el año 2013 se evidencia que el promedio fue de 4.6 días, donde el Tunal fue el hospital con el mayor promedio de horas con un total de 216 horas (9 días), seguido de Simón Bolívar con 161 horas (6.7 días), Kennedy con 60 Horas, (2.5 días) y la Victoria con 8 horas (Menos de 1 día). Santa Clara no reporta dato.

Para el periodo de Enero a Julio de 2014, se evidencia que el promedio fue de 2.3 días, donde el Tunal fue el hospital con el mayor promedio en horas con un total de 144 horas (6 días), seguido de Simón Bolívar con 101 horas (4.2días) y la Victoria con 6 horas (menos de 1 día), Santa Clara no reporta dato.

Cabe destacar que el hospital Santa Clara no reportó el dato para ningún periodo de medición y el Hospital de Kennedy reportó el mismo promedio para los 3 periodos de medición. Los hospitales de alto nivel de complejidad superan el tiempo establecido por la norma en el cual se estipulan 6 horas, este hecho muestra 
claramente la preocupante situación a la cual se enfrentan los pacientes que demandan Referencia para mejorar su situación clínica, también.

\section{NUMERO DE REFERENCIAS NO ATENDIDAS OPORTUNAMENTE POR NO CONTAR CON EL SERVICIO REQUERIDO}

Para este dato encontramos que de los 5 hospitales de alto nivel de complejidad, en el año 2012, sólo el hospital la Victoria reporta el dato, para el año 2013 y e Enero a Julio de 2014, solo 2 reportan el dato, Simón Bolívar y la Victoria, lo cual sería de interés teniendo en cuenta que es importante saber el número de pacientes que no pueden ser aceptados por múltiples casusas y de esta manera brindaría una alerta en la cual se evidencie la oferta y demanda de servicios y la suficiencia de la red para suplirlos. Por lo anterior, no es posible generara un análisis con una muestra poco significativa entre el $20 \%-40 \%$.

\section{DISCUSIÓN}

Se evidencia que la red pública probablemente no presenta sistemas de información eficaces que permitan consolidar, presentar y analizar el comportamiento en datos de interés como: pacientes en proceso de referencia, patologías de mayor incidencia en la consulta de urgencias, EPS con menor o mayor eficacia en la respuesta de referencia, pacientes con comorbilidades secundarias al proceso patológico primario de consulta, promedios de edad en la consulta, pacientes con factores de riesgo asociado, número de pacientes que fallecen en la espera del servicio requerido para mejorar su situación clínica, dato importante que demostraría el incumplimiento de las EPS en su responsabilidad de garantizar la calidad en la atención que se representan a través de la oportunidad y continuidad en la atención en salud. Promedios de estancia hospitalaria de pacientes por patología, oferta y demanda de urgencias, indicadores y tableros de control tendientes a generar estadística con tendencias que permita formular planes de mejora en respuesta a las deficiencias del sistema.

Las administraciones son responsables de presentar el estado epidemiológico de su servicio de urgencias y velar por el cumplimiento de los estándares meta de calidad. Existe una brecha importantísima en información, evidenciado probablemente por la poca cultura de medición y análisis. Es claro que es importante plantear propósitos de calidad en atención, con argumentos medibles.

Los hospitales del Distrito mostraron, cómo para el año 2012 era deficiente la posibilidad de medir la operatividad de los servicios de urgencias, evidenciado con información inexistente o en algunas oportunidades con recolección de datos poco confiable ya que estos fueron tomados de sistemas empíricos mal alimentados, hecho que mejoró para el año 2013 y 2014, pero que continúa estando sujeto a planes de mejora 
Claramente se evidencia que los servicios de urgencias del Distrito presentan deficiencias importantes en la capacidad instalada, equipo médico y unidades de atención, que sumados a una demanda importante de usuarios en el servicio de urgencias, y un proceso de referencia con problemas de resolutividad, ponen en riesgo tanto el bienestar biosicosocial como la vida per sé.

Se deben plantear estrategias por parte de los hospitales del Estado en cabeza de su Gerente y equipo administrativo, EPS, Estado y entes de control para el cumplimiento de la norma que garantice la protección, oportunidad, acceso y la continuidad entre otros, en el proceso de vigilancia y control que velen por la prestación del servicio de salud con calidad, así como el Ministerio de Salud y Protección Social quien debe garantizar el goce del Derecho a la Salud.

A continuación se reflexiona sobre varias situaciones encontradas que requieren de un análisis a mayor profundidad. En el caso de las Instituciones Vista Hermosa y Usme las cuales agrupan 7 CAMls con un perfil poblacional de estrato socioeconómico 1-2, con picos de urgencias los fines de semana, fechas de pago y festividades entre otros, llama la atención que tenga un equivalente de 0 muertes en 2 años y medio. Este dato indicaría que existe una gestión eficaz en el proceso de referencia, hecho que debe ser sujeto de seguimiento teniendo en cuenta las consideraciones expuestas anteriormente. Vale la pena revisar si existe un subregistro o la falta de un sistema de información aplicado que sea eficaz en el reporte de datos reales.

Con base en lo anterior surgen diversas preguntas sobre las referencias en urgencias vitales: ¿por qué tenemos cifras de pacientes que fallecen en espera de la referencia? ¿Dónde está el cumplimiento de la norma? y ¿cuáles son las sanciones al incumplimiento? ¿Cuánto debe ser la cifra para que haya respeto por la vida y la dignidad en el trato y acceso a la salud?, no es coherente que un Estado se conforme con la prestación del servicio de salud, se hace necesario implementar por parte de los entes competentes estrategias que mejoren la prestación del servicio de salud.

\section{CONCLUSIÓN}

- Es necesario mejorar el sistema de información que permita obtener un dato real del número de referencias que se presentan en la red pública del Distrito, sin embargo aunque no es claro si el dato es objetivo, se evidencia un número importante de referencias en el servicio de urgencias.

La Secretaría Distrital de Salud mediante su Circular 030 de 2009, reglamentó la implementación de las herramientas informáticas: Sistema Integral De Referencia y Contrarreferencia -SIRC-Capacidad Instalada y Producción de Servicios (CIP) con el fin de abordar la necesidad existente de 
evaluar y adecuar políticas a nivel Distrital que permitieran identificar la organización y fortalecimiento de los servicios de salud que se prestan a los usuarios del Distrito, donde marzo de 2012, los hospitales iniciaron el reporte del módulo del Registro Único de Referencia (RUR) cuyo objetivo fue mejorar la eficacia en el sector salud en cuanto a cobertura, oportunidad y disponibilidad de los servicios tanto ambulatorios como hospitalarios ofrecidos por las E.S.E.s. Actualmente se evidencia que los hospitales han mejorado la adherencia a este aplicativo, aumentando el registro. Su cumplimiento permitiría contar con un dato objetivo sensible a consolidación y análisis estadístico que proponga estrategias de mejora para el proceso de referencia y contrarreferencia.

- Se evidencia una posible falta de oportunidad en el proceso de referencia de los pacientes en el servicio de urgencias, donde ningún hospital analizado reportó referencia de pacientes en el tiempo establecido por el Decreto 4747 de 2007 (6 horas), lo que demuestra que estos se exponen de manera importante a deterioro biosicosocial e incluso la muerte. Por lo anterior, es importante que las EPS garanticen la oportunidad, el acceso y continuidad en el Derecho a la Salud, donde los entes de control competentes realicen vigilancia al cumplimiento del mismo.

- Se evidencia que existen pacientes que mueren en la espera de ser trasladados a la unidad de servicio médico especializado que requiere para la atención de su patología, hecho inaceptable, teniendo en cuenta la salud como Derecho y la atención médica en condiciones adecuadas para el tratamiento y rehabilitación. Cabe resaltar que probablemente existe un subregistro importante de pacientes, los cuales, por no existir una base de datos formal para su reporte, son difíciles de medir.

Teniendo en cuenta que los niveles de mediano y alto nivel de complejidad no cuentan con capacidad ociosa para suplir las demandas de atención en salud, sino por el contrario se encuentran en emergencia funcional, es claro que puede estar existiendo una insuficiencia de camas importante en el Distrito para responder a las necesidades en salud de la población, especialmente del régimen subsidiado.

Si bien se requieren otros estudios para precisar el número de camas y servicios que hacen falta, lo importante de esta investigación es sugerir que estos datos de medición sean incluidos en el SIRC,(Sistema Integrado de Referencia y Contrarreferencia de la Secretaría Distrital de Salud) donde también se recomienda que desde la Superintendencia Nacional de Salud se generen parámetros de calidad que permitan monitorear, analizar y actuar en las demoras evidenciadas en los procesos de referencia, disminuyendo el riesgo de morbi-mortalidad de los pacientes. Con base a esto se evidencia la necesidad de: 
- Exigir y vigilar el cumplimiento de la norma que hace responsable a las EPS de GARANTIZAR el diseño, organización, documentación y operación del proceso de referencia, donde deben disponer de una red de prestadores de servicios de salud que garantice DISPONIBILIDAD y SUFICIENCIA en TODOS LOS NIVELES DE COMPLEJIDAD.

- La Superintendencia Nacional de Salud debe generar de manera continua estándares de calidad para evaluar tiempos de espera y realizar seguimiento a su cumplimiento.

- Aumentar el número de estudios que evidencien el número de camas y unidades necesarias para atender las necesidades en salud de la población del Distrito.

- Realizar seguimiento al cumplimiento del registro en el SIRC que deben realizar las E.S.E. para mejorar la calidad en los procesos de referencia y contrarreferencia.

- Es necesario idear estrategias que permitan mejorar la prestación del servicio de salud, mejorando la garantía en el derecho al mismo.

- De acuerdo al análisis, se evidencia que la especialidad médica con mayor demanda es Ginecobstetricia, seguido de Medicina Interna, Cirugía general y Pediatría.

- Es importante que se regule el comportamiento de las EPS en respuesta a la oportunidad en la referencia, teniendo en cuenta que en algunos casos, su red de prestadores no es la adecuada para dar respuesta a la demanda de unidades especializadas.

\section{LISTA DE REFERENCIAS}

1. Indicadores de Calidad Reportados por las EAPB a la Superintendencia Nacional de Salud por Circular Única Semestre I - 2.012 Camilo Torres Arboleda , Sergio Gascón Giraldo y Nelcy Otero Dajud. Consultado: 09-012013- 15:28

2. Estadística presentada por el Ministerio de Salud y Protección Social afiliados BDUA [Acceso 16 de Diciembre de 2014] Disponible en: www.minsalud.gov.co/estadisticas/Estadsticas/Afiliados\%20cargados\%20B DUA\%20Abril 2014.zip

3. Organización Panamericana de la Salud / Organización Mundial de la Salud "Análisis del perfíl de salud urbana en Bogotá" Bogotá OPS 2009. 122 pág.ISBN: 978-958-99323-0-8 Director de la publicación: Dr. Teófilo Monteiro Autor Principal: Dr. Ricardo Montezuma Msc. Ph.D. [Acceso 14 de junio de 2015]

http://www.google.com.co/url?sa $=t \& r c t=i \& q=\& e s r c=s \&$ source $=w e b \& c d=4 \& v$ ed=0CDAQFjADahUKEwiltJKBvZDGAhWMzoAKHWwLCFc\&url=http\%3A\% 2F\%2Fwww.paho.org\%2Fcol\%2Findex.php\%3Foption\%3Dcom docman\%2 
6task\%3Ddoc download\%26gid\%3D434\%26Itemid\%3D\&ei=zyB-

VciQGlydgwTslaC4BQ\&usg=AFQjCNFY GozKW9QzGoPtdUmJdXSREfNg Q\&sig2=f6DBf5CCyHgPmw4Rx-PBlg\&bvm=bv.95515949,d.eXY

4. Constitución Política Nacional Titulo II - De los Derechos, las Garantías y los deberes Artículos. 48, 49, y 50 [Acceso 09 de Noviembre de 2014] Disponible en http://www.supersalud.gov.co/supersalud/Default.aspx?tabid=9 6

5. Por la cual se establece el Manual de Actividades, Intervenciones y Procedimientos del Plan Obligatorio de Salud en el Sistema General de Seguridad Social en Salud. Resolución número 5261 de 1994, Agosto 5

6. Indicadores de Calidad Reportados por las EAPB a la Superintendencia Nacional de Salud por Circular Única Semestre I - 2.012 Camilo Torres Arboleda, Sergio Gascón Giraldo y Nelcy Otero Dajud . Consultado: 09-012013- 15:28

7. Decreto 1011 de 2006 [Acceso 09 de Noviembre de 2014] disponible en: http://www.alcaldiabogota.gov.co/sisjur/normas/Norma1.jsp?i=19975

8.Resolución 3047 de 2008 [Acceso 09 de Noviembre de 2014] Disponible http://www.minsalud.gov.co/Normatividad/RESOLUCl\%C3\%93N\%203047\% 20DE\%202008. Pdf

9. Ley 1438 de 2011. [Acceso 09 de Noviembre de 2014] Disponiblehttp://www.alcaldiabogota.gov.co/sisjur/normas/Norma1.jsp?i=41 355

10. Constitución Política Nacional Titulo II - De los Derechos, las Garantías y los deberes Artículos. 48, 49, y 50 [Acceso 09 de Mayo de 2014] Disponible en: http://www.supersalud.gov.co/supersalud/Default.aspx?tabid=96

11. Ley 100 de 1993

12. Decreto 1011 de 2006 [Acceso 09 de Noviembre de 2014] disponible en: http://www.alcaldiabogota.gov.co/sisjur/normas/Norma1.jsp?i=19975

13. Decreto 4747 de 2007 [Acceso 09 de Noviembre de 2014] Disponible http://www.minsalud.gov.co/Normatividad/DECRETO\%204747\%20DE\%202 007.pdf

14. Decreto 4747 de 2007 [Acceso 09 de Noviembre de 2014] Disponible http://www.minsalud.gov.co/Normatividad/DECRETO\%204747\%20DE\%202 007.pdf

15. Decreto 4747 de 2007 [Acceso 09 de Noviembre de 2014] Disponible http://www.minsalud.gov.co/Normatividad/DECRETO\%204747\%20DE\%202 007.pdf

16. Decreto 4747 de 2007 [Acceso 09 de Noviembre de 2014] Disponible http://www.minsalud.gov.co/Normatividad/DECRETO\%204747\%20DE\%202 007.pdf

17. Ley 1438 de 2011. [Acceso 09 de Noviembre de 2014] Disponible en http://www.alcaldiabogota.gov.co/sisjur/normas/Norma1.jsp?i=41355 
18. Resolución 5521 de 2013 [Acceso 09 de Noviembre de 2014] Disponible http://www.minsalud.gov.co/sites/rid/Lists/BibliotecaDigital/RIDE/DE/DIJ/Res oluci\%C3\%B3n\%205521\%20de\%202013.pdf

19. Estadística presentada por el Ministerio de Salud y Protección Social afiliados BDUA [Acceso 16 de Diciembre de 2014] Disponible en: www.minsalud.gov.co/estadisticas/Estadsticas/Afiliados\%20cargados\%20B DUA\%20Abril 2014.zip

20. Decreto 4747 de 2007 [Acceso 09 de Noviembre de 2014] Disponible http://www.minsalud.gov.co/Normatividad/DECRETO\%204747\%20DE\%202 $\underline{007 . p d f}$ 